\title{
Genome description of Phlebia radiata 79 with comparative genomics analysis on lignocellulose decomposition machinery of phlebioid fungi
}

Mari Mäkinen ${ }^{1,4}$, Jaana Kuuskeri ${ }^{1}$, Pia Laine ${ }^{2}$, Olli-Pekka Smolander ${ }^{2,5}$, Andriy Kovalchuk ${ }^{3}$, Zhen Zeng ${ }^{3}$, Fred O. Asiegbu ${ }^{3}$, Lars Paulin², Petri Auvinen ${ }^{2}$ and Taina Lundell ${ }^{1 *}$

\begin{abstract}
Background: The white rot fungus Phlebia radiata, a type species of the genus Phlebia, is an efficient decomposer of plant cell wall polysaccharides, modifier of softwood and hardwood lignin, and is able to produce ethanol from various waste lignocellulose substrates. Thus, $P$. radiata is a promising organism for biotechnological applications aiming at sustainable utilization of plant biomass. Here we report the genome sequence of $P$. radiata isolate 79 originally isolated from decayed alder wood in South Finland. To better understand the evolution of wood decay mechanisms in this fungus and the Polyporales phlebioid clade, gene content and clustering of genes encoding specific carbohydrate-active enzymes (CAZymes) in seven closely related fungal species was investigated. In addition, other genes encoding proteins reflecting the fungal lifestyle including peptidases, transporters, small secreted proteins and genes involved in secondary metabolism were identified in the genome assembly of $P$. radiata.
\end{abstract}

Results: The PACBio sequenced nuclear genome of $P$. radiata was assembled to 93 contigs with $72 X$ sequencing coverage and annotated, revealing a dense genome of $40.4 \mathrm{Mbp}$ with approximately 14082 predicted protein-coding genes. According to functional annotation, the genome harbors 209 glycoside hydrolase, 27 carbohydrate esterase, 8 polysaccharide lyase, and over 70 auxiliary redox enzyme-encoding genes. Comparisons with the genomes of other phlebioid fungi revealed shared and specific properties among the species with seemingly similar saprobic wood-decay lifestyles. Clustering of especially GH10 and AA9 enzyme-encoding genes according to genomic localization was discovered to be conserved among the phlebioid species. In $P$. radiata genome, a rich repertoire of genes involved in the production of secondary metabolites was recognized. In addition, 49 genes encoding predicted $A B C$ proteins were identified in $P$. radiata genome together with 336 genes encoding peptidases, and 430 genes encoding small secreted proteins.

Conclusions: The genome assembly of $P$. radiata contains wide array of carbohydrate polymer attacking CAZyme and oxidoreductase genes in a composition identifiable for phlebioid white rot lifestyle in wood decomposition, and may thus serve as reference for further studies. Comparative genomics also contributed to enlightening fungal decay mechanisms in conversion and cycling of recalcitrant organic carbon in the forest ecosystems.

Keywords: Phlebia radiata, comparative genomics, wood decay, carbohydrate-active enzyme genes, lignin biodegradation, co-regulation, peptidases, secondary metabolism, ABC transporters, small secreted proteins

\footnotetext{
* Correspondence: taina.lundell@helsinki.fi

'Department of Microbiology, Faculty of Agriculture and Forestry, Viikki

Campus, University of Helsinki, Fl-00014 Helsinki, Finland

Full list of author information is available at the end of the article
}

(c) The Author(s). 2019 Open Access This article is distributed under the terms of the Creative Commons Attribution 4.0 International License (http://creativecommons.org/licenses/by/4.0/), which permits unrestricted use, distribution, and reproduction in any medium, provided you give appropriate credit to the original author(s) and the source, provide a link to the Creative Commons license, and indicate if changes were made. The Creative Commons Public Domain Dedication waiver (http://creativecommons.org/publicdomain/zero/1.0/) applies to the data made available in this article, unless otherwise stated. 


\section{Background}

Cellulose and hemicellulose are the most abundant natural, renewable carbohydrate polymers in plant cell walls. In the biodegradation and utilization of the plant biomass, it is considered that access to these carbohydrate polysaccharide feedstocks is restricted due to the compact and ordered plant cell wall lignocellulose composite including regions of crystalline cellulose microfibrils, and the aromatic and heterogenous lignin units [1]. Therefore, the use of plant biomass components for different biotechnological applications such as production of bio-based liquid fuels and chemicals requires both physico-chemical and enzymatic treatments to break the composite structure of lignocellulose [2].

In nature, saprotrophic fungi of the Dikarya phyla Ascomycota and Basidiomycota include thousands of species responsible for the important role in decomposition of plant litter and other biomass-based materials [3, 4]. In particular, cycling of carbon and nutrients in the forest ecosystems is largely dependent on fungal decomposition of dead wood, forest litter and soil organic compounds $[5,6]$. The fungal phylum Basidiomycota contains species with versatile ecological roles and lifestyles such as saprotrophic, plant pathogenic or mutualistic mycorrhizae, and the class Agaricomycetes harnesses the most efficient decomposers of wood lignocellulose [7, 8]. Among the Agaricomycetes, especially fungi in the phlebioid clade of the order Polyporales encompassing corticioid and polyporoid basidiocarpforming species demonstrate high potential for biotechnological applications due to their ability to attack all chemical components of lignocellulose including lignin $[9,10]$.

Phylogenetically, the Polyporales phlebioid clade fungi may be further divided into genus level sub-clades of Phlebia, Phanerochaete and Byssomerulius [10, 11]. The most studied species with the first published Basidiomycota sequenced genome is Phanerochaete chrysosporium [12], which is considered as the model white rot fungus for wood decay studies. Since then, draft genomes of several other phlebioid species, also from the genera Bjerkandera and Phlebiopsis, have been annotated as part of the DOE JGI 1000 Fungal Genomes and related community projects [13-16]. Phlebia radiata is a phlebioid white rot fungus of the Polyporales family Meruliaceae [17] and the type species of genus Phlebia. The Finnish isolate $P$. radiata 79 has been widely studied showing the diverse ability to decompose and convert different wood types and plant biomass, to degrade harmful organic compounds, to modify lignin, and to secrete a wide variety of carbohydrate-active enzymes (CAZymes) and oxidoreductases [9, 18, 19]. In particular, the oxidoreductase production properties vital for biological attack on lignins and lignin-like compounds have been of interest [20,21]. Individual genes encoding class-II lignin peroxidases [22], two divergent class-II manganese peroxidases [23], and two laccases [24, 25] have been cloned and characterized. Transcripts and secreted protein products of these together with an array of CAZyme-encoding genes of $P$. radiata acting against plant cell wall polysaccharides were identified when the fungus was grown on spruce wood [26].

Advances in the development of next-generation genome sequencing platforms have enabled detailed and costeffective investigation of genomic content of diverse fungi. The Phlebia clade includes three genome-sequenced species that are Phlebia brevispora [7], Phlebia centrifuga [27], and Phlebia radiata presented in this study. Among the Phanerochaete clade, genomes of Phanerochaete chrysosporium [28], Phanerochaete carnosa [29], Bjerkandera adusta [7] and Phlebiopsis gigantea [15] have been assembled and annotated. The number of genome-sequenced fungi representing different lifestyles has been accumulating particularly within the 1000 Fungal Genomes project [13, 16, 28 . The gene content and genomic arrangement apparently reflect the lifestyle of an organism; in fungi, comparative genomics approaches have given explanations for e.g. brown rot versus white rot decay of wood [8, 13, 30], and divergent and specific mycorrhizal associations with tree and other plant roots [31]. With the aid of whole-genome sequencing together with comparative genomics, genes encoding enzymes and proteins vital for the organism in its natural habitat, evolutionary relationships between fungal species and clades may as well be predicted [8, 13, 14, 2831]. Comparative genomics studies may also enable identification of novel activities important for plant biomass degradation and deepen the overall understanding of the fungal wood decay genetics and mechanisms.

In this study, high-throughput genome characterization of $P$. radiata as well as comparative analysis on genes associated with the plant cell wall degradation among the phlebioid fungal species (altogether seven species genomes) were elucidated. Special attention was given to the CAZyme-encoding genes involved in cellulose, hemicellulose and pectin degradation, and in oxidative attack on lignin. Other genes reflecting the lifestyle of the fungus including peptidase, $\mathrm{ABC}$ transporter, small secreted protein (SSP) and genes involved in secondary metabolism were also identified in the genome and discussed.

\section{Results}

Characteristics of the Phlebia radiata genome assembly

In total, the genome assembly contained 93 contigs as unitigs at the average of $72 \mathrm{X}$ sequencing coverage. The assembly included the mitochondrial mtDNA [82] in a single contig which was further removed, resulting in final assembly of 40.4 Mbp (haploid genome size) containing 92 nuclear contigs as scaffolds (Table 1). Mean read length was 5552 bp, average contig size 436607 bp, maximal contig size 3403443 bp, minimal contig 
Table 1 Summary of the genome assembly features of the phlebioid fungal genomes included in the comparative study

\begin{tabular}{|c|c|c|c|c|c|c|c|}
\hline Genome features & P. radiata & P. brevispora & P. centrifuga & B. adusta & P. gigantea & P. carnosa & P. chrysosporium \\
\hline Assembly size (Mbp) & 40.41 & 49.96 & 34.85 & 42.73 & 30.14 & 46.29 & 35.15 \\
\hline \# of contigs & 92 & 3178 & 3667 & 1263 & 1195 & 2272 & 1253 \\
\hline \# of scaffolds & 92 & 1645 & 3022 & 508 & 573 & 1137 & 232 \\
\hline \# of scaffolds $\geq 2 \mathrm{kbp}$ & 92 & 1645 & 1652 & 508 & 506 & 1136 & 204 \\
\hline Scaffold L50 & 8 & 12 & 201 & 13 & 72 & 6 & 8 \\
\hline Scaffold N50 (Mbp) & 1.98 & 1.31 & 0.05 & 1.03 & 0.12 & 3.53 & 1.91 \\
\hline \# of gaps & 0 & 1533 & 645 & 755 & 622 & 1135 & 1021 \\
\hline Average gene lenght (bp) & 1847 & 1627 & 1378 & 1703 & 1714 & 1765 & 1684 \\
\hline Average transcript length (bp) & 1463 & 1274 & 1134 & 1388 & 1380 & 1446 & 1401 \\
\hline Average exon length (bp) & 227 & 225 & 274 & 248 & 230 & 269 & 259 \\
\hline Average intron length (bp) & 72 & 78 & 80 & 71 & 69 & 75 & 66 \\
\hline Average protein length (bp) & 488 & 400 & 378 & 406 & 411 & 384 & 408 \\
\hline Exons per gene & 6.46 & 5.66 & 4.14 & 5.59 & 6 & 5.36 & 5.41 \\
\hline \# of gene models & 14629 & 16170 & 13785 & 15473 & 11891 & 13937 & 13602 \\
\hline
\end{tabular}

Data were collected from the JGI MycoCosm (genome.jgi.doe.gov/programs/fungi/index.jsf)

size 5203 bp and GC content $53 \%$. In total, 14082 unique gene models and 547 possible splice variants were recognized by the aid of available RNA sequencing data using the $a b$ initio gene prediction software BRAKER1.

$P$. radiata genome assembly was compared with other phlebioid clade fungal genomes $[10,11]$ including the species Phlebiopsis gigantea, Phlebia brevispora, Phlebia centrifuga, Bjerkandera adusta, Phanerochaete chrysosporium and Phanerochaete carnosa (Table 1). Genomic data of all the species are available at the Joint Genome Institute (JGI) MycoCosm (genome.jgi.doe.gov/programs/fungi/ index.jsf) [16]. Noticeable is the quality of $P$. radiata genome with 0 gaps in the closed and gene annotated assembly, and with contigs extended to $<100$ scaffolds (Table 1 ). Scaffold L50 value $1.98 \mathrm{Mbp}$ is near to estimated median average chromosomal length (between 0.8 - 3.5 Mbp). The species $P$. gigantea, $P$. centrifuga and $P$. chrysosporium had somewhat smaller genome sizes (30-35 Mbp) than the other phlebioid species. The average length of $P$. radiata gene and transcript models were the largest among the studied fungi (1847 bp and $1463 \mathrm{bp}$, respectively). Noticeable is also the highest number of recognized intron-exon junctions in the gene models of $P$. radiata (average exon number 6.46 per gene; Table 1).

\section{Functional annotation of the $P$. radiata gene models}

The presence of $5^{\prime}$ upstream open reading frames (uORFs), high number of introns and very short exons (from a few to even less than one codon in some cases) were found to be typical for $P$. radiata genes. For translated 365 gene models, no blastp or protein domain hits were obtained. According to Gene Ontology classifications (Fig. 1a, b), the majority of $P$. radiata predicted proteins were assigned to the functional terms of "Catalytic activity", "Binding", "Metabolic process" and "Cellular process" (Fig. 1b).

\section{GO enrichment analysis}

GO enrichment analysis was conducted based on the previous RNA-seq transcriptome data of $P$. radiata cultivated both on solid spruce wood (2-week and 4-week time points) and for comparison, on liquid malt extract medium (2-week time point) [26]. GO terms overrepresented among the genes which were up-regulated at both time points on spruce wood included the terms of "carbohydrate metabolic process", "cell wall", "oxidoreductase activity", "hydrolase activity, acting on glycosyl bonds", "extracellular region", "external encapsulating structure", "catalytic activity", "cell wall organization or biogenesis" and "lipid metabolic process" (Additional file 1). The enriched term of "carbohydrate metabolic process" was statistically the most significant (P-value $1.03 \times 10^{-19}$ ). At the four week time point on spruce wood substrate, the most enriched GO terms among the up-regulated genes included the "transmembrane transport" and "establishment of protein localization to membrane". Much greater number of GO terms were enriched only among the genes which were up-regulated at the 2-week time point on spruce wood. These included for example GO terms referring to organic acid metabolism ("carboxylic acid metabolic process", "organic acid metabolic process", "oxoacid metabolic process") and to translation ("structural constituent of ribosome", "ribosome", "translation", "ribonucleoprotein complex biogenesis", "intracellular ribonucleoprotein complex", "ribosome biogenesis", "ribonucleoprotein complex"). 


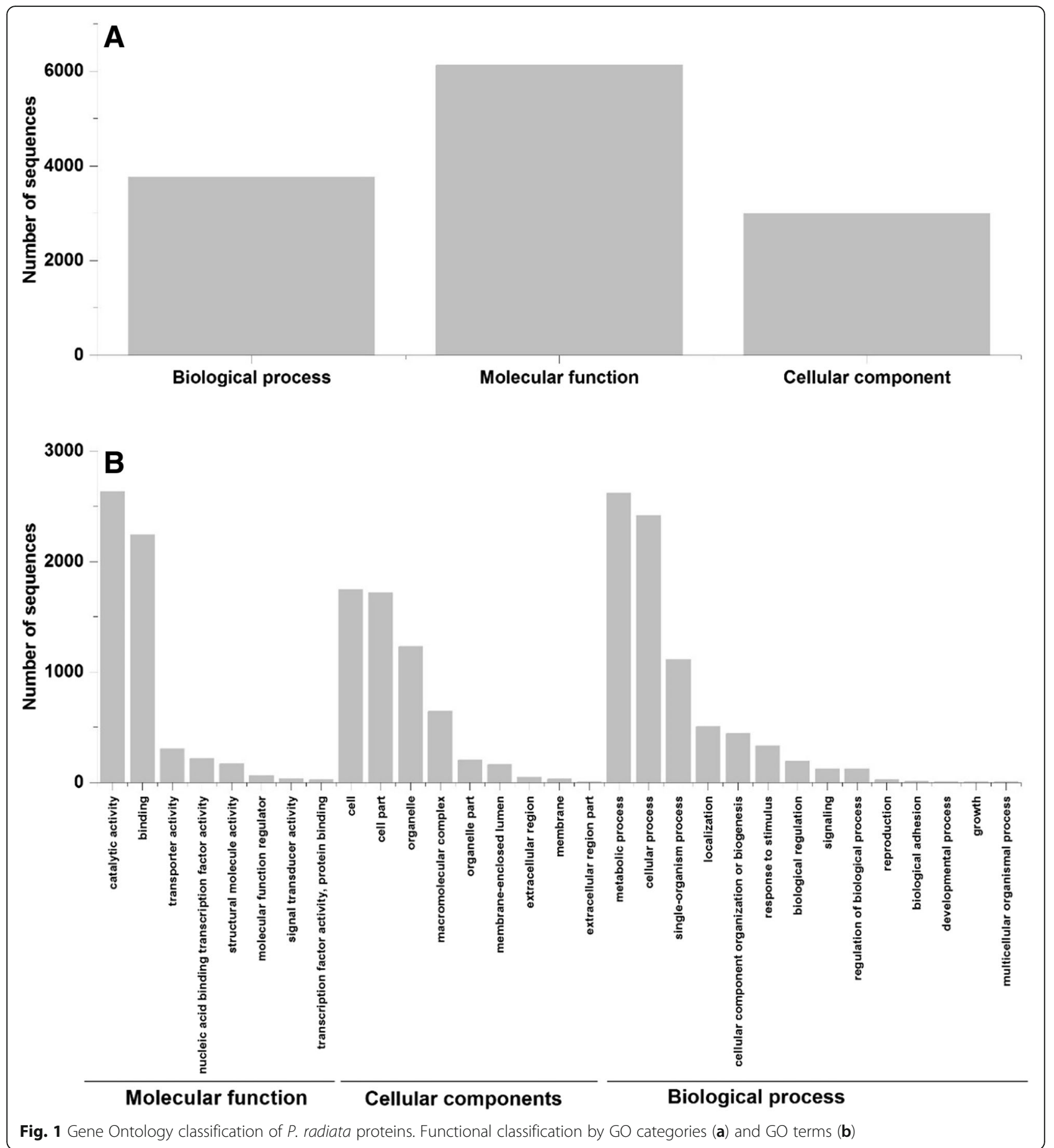

\section{Carbohydrate-active enzyme genes}

Carbohydrate-active enzyme encoding genes of $P$. radiata were annotated previously during the combinatory transcriptome and proteome study on wood [26]. Consequently, a comparative analysis on the number of CAZyme-encoding genes of $P$. radiata and six other sequenced phlebioid species of Polyporales fungi (Table 2) was performed.
In total, 209 glycoside hydrolase (GH), 27 carbohydrate esterase $(\mathrm{CE})$ and 8 polysaccharide lyase (PL) genes were identified in the $P$. radiata genome (Additional file 2). Of these genes, $76 \mathrm{GHs}, 15 \mathrm{CEs}$ and $1 \mathrm{PL}$ were annotated to putatively encode enzymes involved in breakdown of plant cell wall lignocellulose. In addition, twelve auxiliary activity family 9 (AA9) lytic polysaccharide monooxygenase (LPMO) encoding genes and three genes coding for AA14 
Table 2 Number of the identified CAZyme-encoding genes involved in breakdown of plant cell wall lignocellulose components in the genomes of the studied phlebioid fungi

\begin{tabular}{|c|c|c|c|c|c|c|c|}
\hline Cellulose active & P. radiata & P. brevispora & P. centrifuga & B. adusta & P. gigantea & P. carnosa & P. chrysosporium \\
\hline $\mathrm{GH} 1$ & 2 & 2 & 2 & 2 & 2 & 2 & 2 \\
\hline $\mathrm{GH} 3$ & 10 & 8 & 7 & 9 & 9 & 11 & 10 \\
\hline GH5_5 & 4 & 4 & 2 & 4 & 4 & 6 & 2 \\
\hline GH5_22 & 2 & 2 & 2 & 2 & 2 & 2 & 2 \\
\hline $\mathrm{GH} 6$ & 1 & 1 & 1 & 1 & 1 & 1 & 1 \\
\hline $\mathrm{GH} 7$ & 6 & 4 & 3 & 5 & 5 & 5 & 8 \\
\hline $\mathrm{GH} 9$ & 1 & 1 & 1 & 1 & 1 & 1 & 1 \\
\hline $\mathrm{GH} 12$ & 2 & 2 & 2 & 2 & 3 & 3 & 2 \\
\hline $\mathrm{GH} 44$ & 1 & 2 & 1 & 0 & 0 & 0 & 0 \\
\hline $\mathrm{GH} 45$ & 3 & 3 & 1 & 1 & 1 & 1 & 2 \\
\hline GH131 & 2 & 4 & 2 & 3 & 2 & 2 & 3 \\
\hline
\end{tabular}

Hemicellulose active

CE1
CE5
CE15
CE16
GH2
GH5_7
GH10
GH11
GH27
GH29
GH31
GH35
GH43
GH51
GH74
GH95
GH115

Pectin active

$\begin{array}{ll}\text { CE8 } & 2 \\ \text { CE12 } & 0 \\ \text { GH28 } & 7 \\ \text { GH53 } & 1 \\ \text { GH78 } & 2 \\ \text { GH88 } & 1 \\ \text { GH105 } & 3 \\ \text { PL1 } & 0 \\ \text { PL4 } & 1\end{array}$

Auxiliary redox enzymes

$\begin{array}{lll}\text { AA1 } & 7 & 11 \\ \text { AA2 } & 10 & 15 \\ \text { AA3 } & 32 & 39\end{array}$

$\begin{array}{ll}11 & 6 \\ 15 & 8 \\ 39 & 23\end{array}$

2
21
39

5
9
23

10

5

$11 \quad 15$

36 
Table 2 Number of the identified CAZyme-encoding genes involved in breakdown of plant cell wall lignocellulose components in the genomes of the studied phlebioid fungi (Continued)

\begin{tabular}{|c|c|c|c|c|c|c|c|}
\hline Cellulose active & $P$. radiata & P. brevispora & $P$. centrifuga & B. adusta & P. gigantea & P. carnosa & P. chrysosporium \\
\hline AA3_1 (CDH) & 1 & 1 & 1 & 1 & 1 & 1 & 1 \\
\hline AA5 & 10 & 8 & 6 & 7 & 6 & 6 & 7 \\
\hline AA9 & 12 & 12 & 11 & 28 & 15 & 11 & 16 \\
\hline AA14 & 3 & 2 & 2 & 3 & 3 & 2 & 2 \\
\hline DyP & 1 & 3 & 2 & 10 & 4 & 1 & 0 \\
\hline HTP & 5 & 2 & 4 & 4 & 4 & 3 & 3 \\
\hline
\end{tabular}

CAZy GH, CE, PL and AA classes, dye-decolorizing peroxidases (DyP), and heme-thiolate peroxidases (HTP) are indicated

lytic xylan oxidases were recognized in the genome. The carbohydrate-binding module (CBM) for cellulosebinding domain (IPR000254) was detected in 32 genes coding for AA9 LPMOs, and exoglucanases of the families GH6, GH7 and GH131, one GH3 $\beta$-glucosidase, endoglucanases of the families GH5 and GH45, xylanases of the families GH10 and GH11, GH5 mannanases, one CE1 acetyl xylan esterase, one CE15 glucuronoyl esterase, and one CE16 acetylesterase (Additional file 2). In addition, four CBM1 domain-containing proteins with no homology to CAZyme activity catalytic domains were detected in $P$. radiata. One of these genes encodes a putative carbohydrate-binding iron reductase whereas another protein with CBM1 demonstrated homology to phosphodiesterases.

\section{Cellulose breakdown}

As could be expected, all the studied phlebioid genomes possess genes encoding activities for the hydrolytic decomposition of polymeric cellulose including cellobiohydrolases, endoglucanases and $\beta$-glucosidases (Fig. 2). Largest number of cellulolytic genes was found in the CAZy families GH3 and GH7 as well as in the auxiliary oxidoreductase family AA9 (Fig. 2). Typical for Polyporales white rot fungi, one gene encoding GH6 (non-reducing end active cellobiohydrolase) was conserved in all phlebioid genomes whereas the number of genes coding for GH7 (reducing end active cellobiohydrolases) ranged from three up to eight (Table 2). P. radiata genome harbors six genes coding for GH7 proteins, of which three are unique and three have shared protein homology, indicating sequential gene duplications. The gene models minus.g2003 and plus.g2026 contain only 10 and 14 nt (nucleotide) differences, respectively. The third gene model minus.g8589 contains two 44 nt differences and 2 nt deletions resulting in e.g. variation in translation for two codons in comparison to the other two (together identical) protein models. The single nucleotide polymorphism (SNP) detected among the duplicates occurs at the codon third position. Variations in the GH7 proteins of $P$. radiata and the other phlebioid fungi are frequent in the protein model linker region separating the catalytic domain and fused CBM1 domain.

CAZy family GH5 comprises hydrolytic activities on various polysaccharide substrates present in the plant cell wall and in the fungal cell wall [32]. Hence, GH5

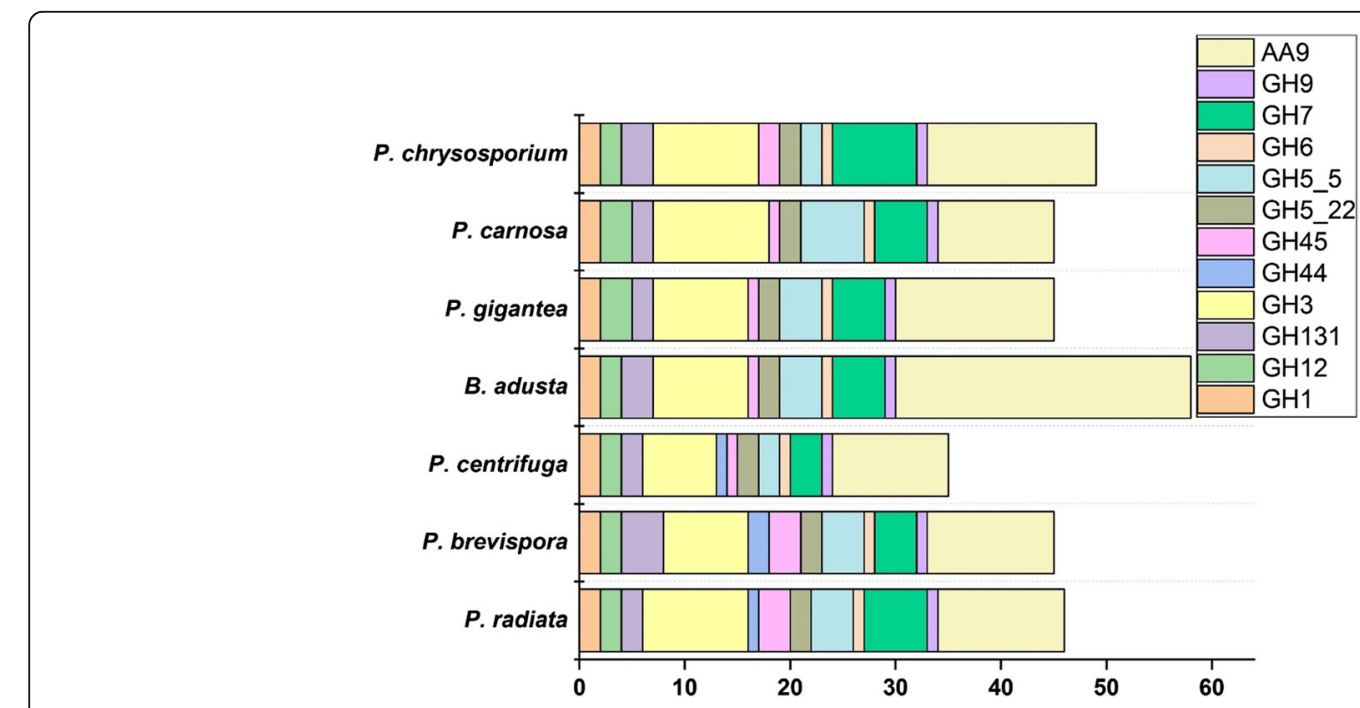

Fig. 2 Number of cellulose decomposing-enzyme coding genes in the genomes of the phlebioid fungi 
sub families 5, 7 and 22 were included in this comparative study. Family 5_5 includes endo- $\beta$-1,4-glucanase (EC 3.2.1.4) activities, family $5 \_7$ endo- $\beta-1,4$-mannanase activities (EC 3.2.1.78) and family 5_22 activities of endobeta-1,4-glucanase and $\beta$-xylosidase. Of the seven phlebioid genomes, $P$. centrifuga and $P$. chrysosporium possess only two GH5_5 endo- $\beta$-1,4-glucanase encoding genes whereas the other genomes contain at least four genes (Table 2). Interestingly, the family GH44 endoglucanases were identified as one or two gene copies only in the three Phlebia species. P. radiata and P. brevispora have three genes encoding GH45 endoglucanase, whereas the other phlebioid fungi contained less, one or two genes. Noteworthy is that all phlebioid genomes possess one copy of a putative GH9 cellulase encoding gene.

All phlebioid fungal genomes apparently harbor two GH1 $\beta$-glucosidase-encoding genes, whereas seven or more GH3 family $\beta$-glucosidase-encoding genes were identified (eight genes in P. radiata) (Table 2, Fig. 2). CAZy family GH3 is a complex family including also activities affecting the fungal cell wall [33]. Two to three GH12 family genes encoding putative endoglucanases and xyloglucan-specific endo- $\beta$-1,4-glucanases were equally present in the phlebioid fungi. In addition to the traditional endoglucanase and cellobiohydrolase-encoding genes, the phlebioid genomes contain 2-4 putative members of the family GH131 broad specificity $\beta$-glucanases. One of the two $P$. radiata $\mathrm{GH} 131$ protein models included a Cterminal CBM1 domain indicating possible attachment to polymeric cellulose. In addition to the hydrolytic cellulolytic enzymes, all phlebioid genomes harbor a large number (11-28) of AA9 lytic polysaccharide monooxygenase encoding genes (Fig. 2) involved in oxidative decomposition of cellulose [34].

\section{Hemicellulose degradation}

Genomes of the phlebioid fungi possess a wide array of genes encoding all the necessary activities for the decomposition of glycosidic and ester linkages of diverse hemicelluloses (Fig. 3). Largest number of genes were detectable in the carbohydrate esterase family CE16 (acetylesterase activity) ranging from 5 to 15 genes per genome (Table 2), and glycoside hydrolase families GH10, GH31 and GH43 (Fig. 3). However, the GH29 $\alpha$-L-fucosidase encoding genes appear to be specific for the three Phlebia species (Table 2) whereas the GH11 endoxylanase encoding genes were absent in the genomes of $P$. brevispora, $P$. centrifuga and $B$. adusta. Interestingly, $P$. gigantea genome harbors two genes for GH11 endoxylanase while missing the GH95 $\alpha$ fucosidase activity genes. A putative CE5 acetyl xylan esterase gene was detected only for P. brevispora.

Genes encoding the novel AA14 oxidoreductase family of lytic xylan oxidases/monooxygenases were identified in $P$. brevispora, $P$. gigantea, $B$. adusta, $P$. chrysosporium and $P$. carnosa in a previous study [35]. For $P$. radiata, three putative genes with translated amino acid sequence homology to the Pycnoporus coccineus AA14 proteins were identified by blastp search of the genome protein models (Table 2). For $P$. centrifuga, two possible AA14 homologs were found by blastp search against the MycoCosm genome data. Interestingly, two of the $P$. radiata AA14 genes encode proteins with an extension in the C-terminus ( $3^{\prime}$ end) whereas the third gene protein model is shorter in the C-terminus than the corresponding P. coccineus AA14 homologs. All three $P$. radiata AA14 protein models demonstrate a conserved N-terminal histidine after the signal sequence cleavage site, similar to the features of the $P$. coccineus proteins [35]. Whereas one of the AA14 genes was highly up-regulated in $P$. coccineus cultivated on pine and aspen substrates [36], the $P$.

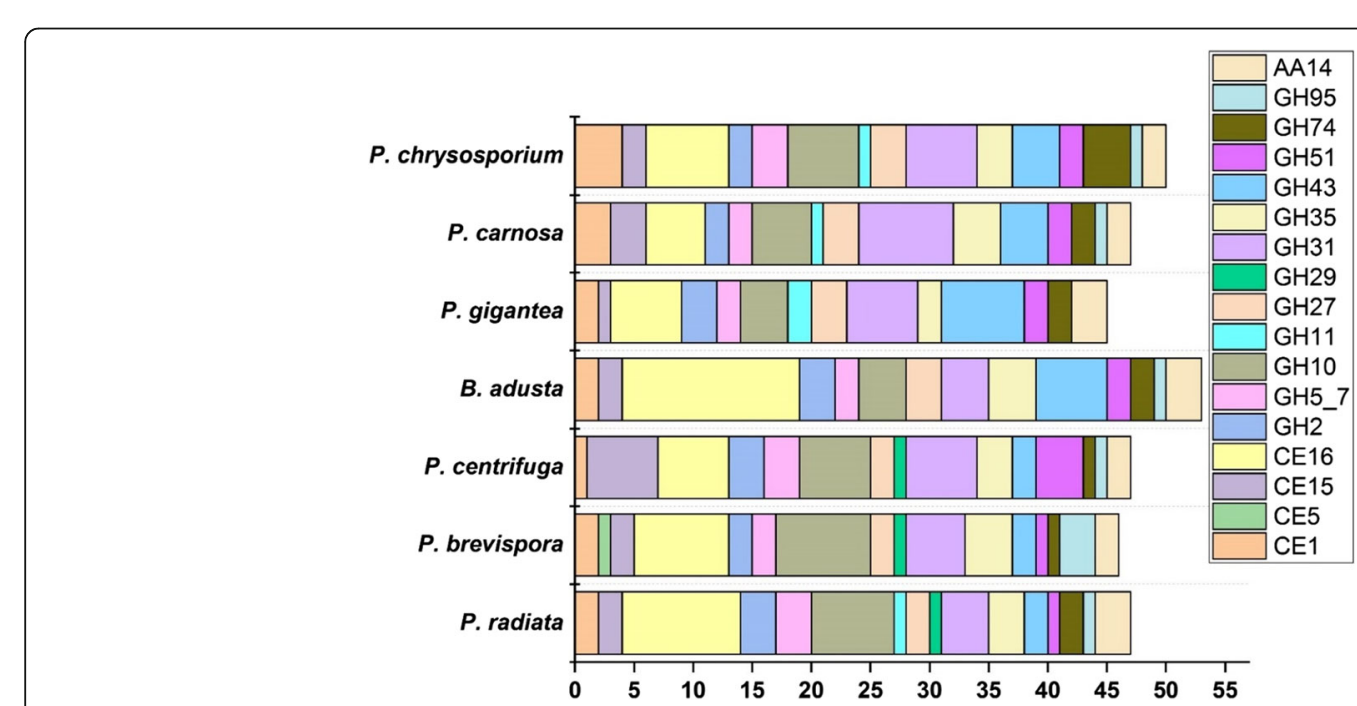

Fig. 3 Number of genes encoding hemicellulose-decomposing enzymes in the genomes of the phlebioid fungi 
radiata homologs were more constitutively expressed on spruce wood [26] (Additional file 2).

\section{Pectin degradation}

From the CAZy families including pectin-decomposing activities, GH28, GH105 and CE8 families had the largest number of genes (Fig. 4). The number of family GH28 polygalacturonase and rhamnosidase encoding genes was relatively large (4-10 genes) in the phlebioid genomes, especially in the P. gigantea genome (Table 2). Also, four genes encoding CE8 pectin methylesterases were identified in P. gigantea genome. Differences were noticed in the CE12 family including acetylesterase activity against pectin with genes detected only in B. adusta and P. gigantea, and family GH105 rhamnogalacturonyl and glucuronyl hydrolase activity encoding genes which were identified (1-3 genes) only in the genomes of $P$. radiata, $P$. centrifuga and $B$. adusta. Of the potential pectin-acting lyases, one gene encoding family PL4 rhamnogalacturonan endolyase activity was restricted to the three Phlebia species and B. adusta, whereas family PL1 pectin/pectate lyase (one gene) was specific for B. adusta (Fig. 4, Table 2).

\section{Lignin conversion}

In total, 65 CAZy auxiliary activity (AA) class genes encoding lignin-modifying and associated redox activities were identified in P. radiata genome (Additional file 2). All seven phlebioid species harness multiple AA1 laccases/ferroxidases/laccase-like multicopper oxidases and multiple AA2 family class-II heme-including, lignin and manganese peroxidases (LiP, MnP) (Table 2, Fig. 5). Notably, the three Phlebia species include several genes encoding both long-MnP and short-MnP AA2 peroxidases $[14,23]$ together with lignin peroxidase encoding genes, whereas $B$. adusta genome encodes one additional class-
II versatile peroxidase (VP) [13, 14]. Auxiliary enzymes possibly involved in providing hydrogen peroxide for the lignin-modifying peroxidases include, for example, family AA3 glucose-methanol-choline (GMC) family oxidases (glucose/aryl alcohol/alcohol/pyranose oxidases) and AA5 copper radical oxidases (galactose/glyoxal oxidases). Members of these gene families were present in the phlebioid genomes. Importantly, one copy of the cellulolytic and lignin-attacking oxidative activity interlinking AA3_1 oxidoreductase family cellobiose dehydrogenase $(\mathrm{CDH})$ encoding gene is present in all of the phlebioid genomes. In addition, $P$. radiata genome includes one gene encoding a putative dye-decolorizing peroxidase (DyP) and five genes encoding putative chloroperoxidase-like hemethiolate peroxidases (HTP) [37]. Presence of a few putative HTPs and 1-4 DyPs is a common feature among the phlebioid fungi (Table 2), thereby extending their functional potential in oxidation and activation of lignin-like and various phenolic compounds [37]. Exceptional is B. adusta with 10 potential DyP encoding genes recognized in the genome, and the absence of DyP genes in P. chrysosporium (Table 2, Fig. 5).

\section{Genomic clustering of CAZyme genes}

Carbohydrate-active enzyme encoding genes under consorted expression and regulation mechanisms were searched from the $P$. radiata genome assembly according to the criteria of (i) close genomic coordinates, and (ii) up-regulation of gene expression on spruce wood as growth substrate in our pervious study [26] (Additional file 3). The most interesting clusters include genes encoding activities against plant cell wall components and genes showing strong co-regulation. $P$. radiata CAZyme genes were identified and annotated in 33 unitigs whereas the majority ( $54 \%$ ) of the CAZyme genes were

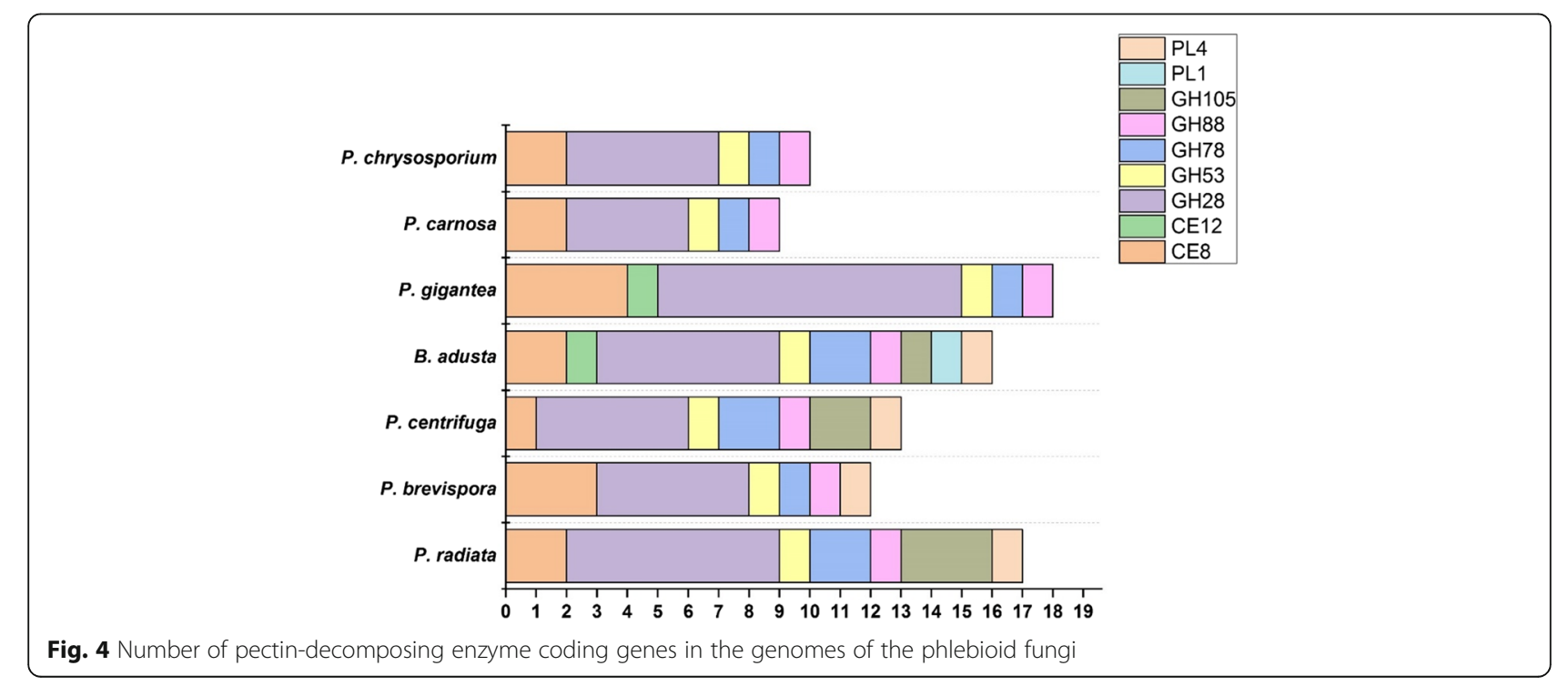




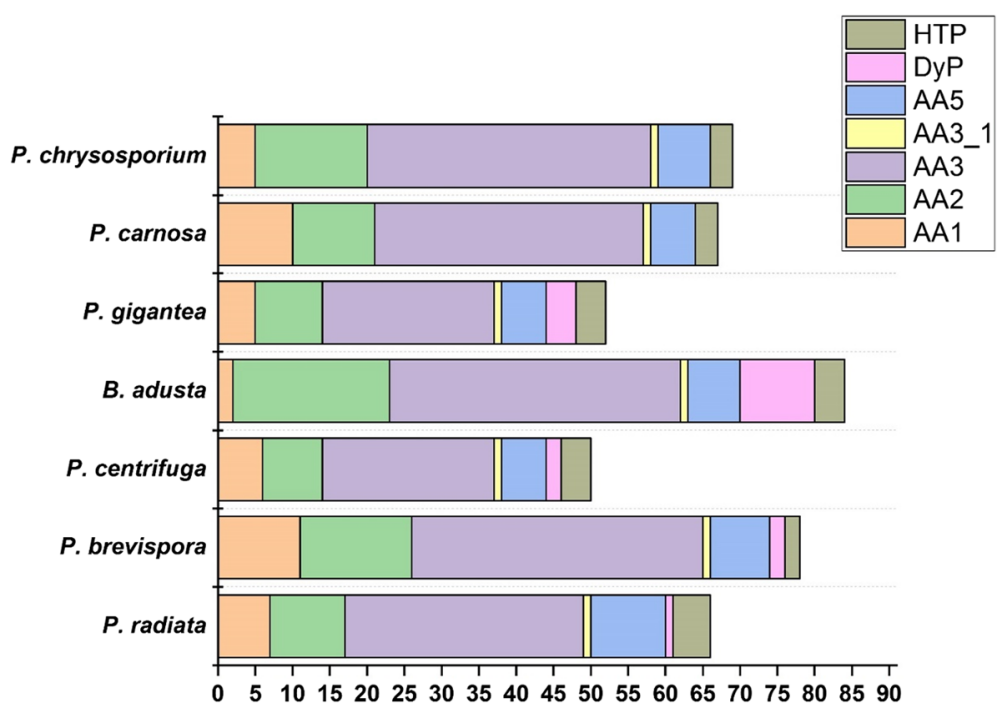

Fig. 5 Number of lignin-modifying and auxiliary oxidoreductase-coding genes in the genomes of the phlebioid fungi

assigned to seven distinct unitigs. When applying the sliding window approach [38], 55 CAZyme genes were assigned to clusters. Minimum of three CAZyme genes in a window of maximum of 11 genes was considered as a CAZyme cluster. The size of the cluster window was calculated by dividing the number of $P$. radiata gene models (14082) with the number of annotated CAZyme genes (244). Hence, when random distribution of CAZyme genes was expected, one CAZyme gene should appear once within 58 subsequently ordered genes. When the three CAZyme genes of the cluster are expected to be separated from each other by less than a fifth of the average distribution number, the size of the window was $11(0.2 \times 58)$. A total of 17 clusters were detected according to these criteria (Additional file 3). In addition, interesting clusters including two CAZyme genes next to each other and encoding plant cell wall degrading activities are also included in the data set (Additional file 3).

In general, no clear tendency for tight clustering according to genomic localization could be asserted to highly similar expression patterns of the multiple genes encoding diverse CAZy classes and families. However, clustering, and in some cases, concerted expression and possible co-regulation of the members of GH10 (xylanase activity) and AA9 (LPMO) family genes was detected (Figure 6). There is a cluster of four putative GH10 endo-beta-1,4-xylanase encoding genes in near location and antisense orientation in the unitig 9 of $P$. radiata genome assembly (Fig. 6a). Three of the genes were up-regulated on spruce wood substrate. In unitig 9, two AA9 lytic polysaccharide monooxygenase encoding genes are neighbours and strongly up-regulated at both time points on spruce wood substrate (Fig. 6b). In unitig
83, three AA9 genes and a non-CAZyme protein encoding gene (minus.g10275) form a cluster (Fig. 6c). From the three AA9 genes, two are strongly up-regulated on spruce whereas the third AA9 gene was up-regulated only at the two-week time point of spruce cultivation. In unitig 6, another set of additional two AA9 genes are located next to each other but only one of the genes was up-regulated on spruce wood (Additional file 3).

Clustering of GH10 enzyme encoding genes was similarly recognized to be shared by the three species of the genus Phlebia ( $P$. radiata, $P$. brevispora, $P$. centrifuga) but not in the three other phlebioid fungi studied (Table 3). Clustering of 2-6 GH10 genes is interrupted in the Phlebia genomes by a maximum of three non-CAZyme protein encoding genes. However, considering AA9 LPMO encoding genes, majority of the phlebioid species demonstrated several AA9 gene clusters in different scaffolds (2-4 clusters) except for the $P$. centrifuga showing only one cluster of two AA9 encoding genes (Table 4).

Other CAZyme gene clusters of interest and identified in $P$. radiata genome included, for example, two GH45 endoglucanase encoding genes located next to each other in unitig 0 while only one of the genes was strongly up-regulated on spruce wood (Additional file 3) . Of three CE16 carbohydrate esterase encoding genes forming a cluster in the same unitig, two were upregulated on spruce wood whereas one gene was downregulated. Two up-regulated GH35 genes were identified next to each other in unitig 23. In addition, two GH3 $\beta$ glucosidase encoding genes located next to each other in unitig 59 and two GH28 encoding genes next to each other in unitig 96, but these genes were not co-regulated (one gene was up-regulated while the other was downregulated) thereby indicating individual regulation of 
A

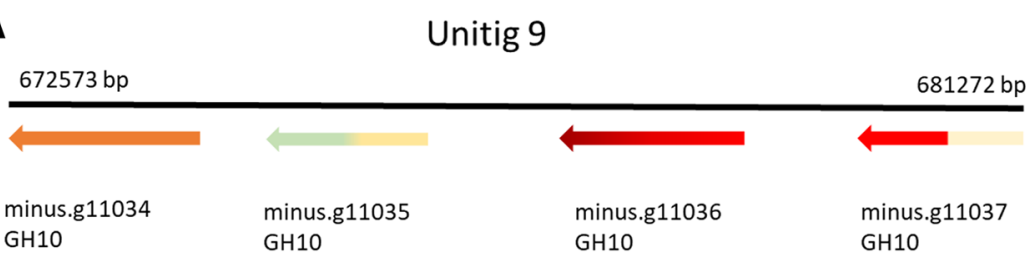

B Unitig 9

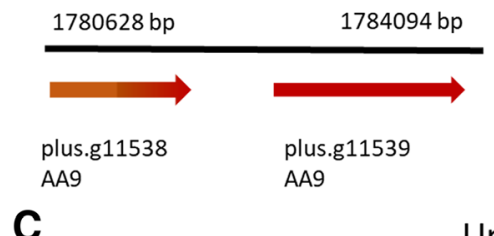

C

Unitig 83

\begin{tabular}{lll}
$124277 \mathrm{bp}$ & & $133397 \mathrm{bp}$ \\
\hline & minus.g10274 & \\
minus.g10273 & AA9 & minus.g10275 \\
AA9 & & plus.g10374
\end{tabular}

Fig. 6 Clustering and co-regulation of GH10 endo-1,4- $\beta$-xylanase (a) and AA9 LPMO encoding genes (b, c) of P. radiata. Intensity of the color indicates the scale of up- or down-regulation (dark red for high up-regulation, green for down-regulation, yellow for no significant difference) of gene expression on spruce wood substrate [26]. Direction of the arrow indicates gene location and orientation (on plus or minus strand) in the unitigs of the genome assembly (this study). The arrowhead indicates the 2-week time point of spruce wood cultivation whereas the end of the arrow refers to the 4-week time point. Beginning and end of the cluster (as genomic coordinates) is marked above the unitig. Gene model minus.g10275 in unitig 83 encodes a non-CAZyme protein

their expression. On the contrary, two family GH5 annotated genes were found adjacently located in unitig 117 and convergently expressed - up-regulated at both time points on the spruce wood substrate. Moreover, both of the encoded proteins demonstrated high homology with a specific $P$. chrysosporium $\beta$-xylosidase that cleaves xylan hemicellulose chains synergistically with endoxylanases [39].

Of the ten identified AA2 class-II peroxidase encoding genes of $P$. radiata targeted to lignin modification (Table 2), lip3 and lip4 genes are closely located in the genome, and separated only by one gene encoding a hypothetical protein in unitiq 9. Surprisingly, the genes were not co- regulated on spruce wood substrate [26]. Similarly, the AA1 laccase encoding $l a c c 1$ and $l a c c 2$ genes of $P$. radiata located in unitig 55 are neighbours and possess similar expression profiles but, however, were not strongly upregulated on spruce wood [26]. In unitig 70, one AA8 iron reductase encoding gene is seemingly co-expressed with a GH128 $\beta$-glucanase encoding gene. Interestingly, the only cellobiose dehydrogenase $(\mathrm{CDH})$ encoding gene of $P$. radiata was recognized to situate next to a putative catalase encoding gene in the same unitig 70 , with concurrent up-regulation at both time points on spruce wood. Of the potential hydrogen peroxide producing extracellular enzymes, three AA5 copper radical oxidase encoding genes

Table 3 Genomic clusters of GH10 endoxylanase encoding genes in the genome assemblies of the phlebioid fungi

\begin{tabular}{llll}
\hline Fungus & Cluster location in the genome assembly & Number of genes in the cluster & Number of non-CAZyme genes in the cluster \\
\hline P. radiata & Unitig 9/Scaffold 8:672573-681272 & 4 & 0 \\
P. brevispora & Scaffold 12:834597-856661 & 9 & 3 \\
P. centrifuga & Scaffold 2925:6494-13943 & 3 & 0 \\
B. adusta & absent & - & - \\
P. gigantea & absent & - & 1 \\
P. carnosa & Scaffold 3:3347462-3351815 & 3 & - \\
P. chrysosporium & absent & - & -
\end{tabular}

Locations of $P$. radiata gene models are indicated as original assembly unitig positions, and as scaffold positions of the MycoCosm genome repository. Other data were retrieved from the MycoCosm 
Table 4 Genomic clusters of AA9 encoding genes in the genome assemblies of the seven phlebioid fungi

\begin{tabular}{|c|c|c|c|}
\hline Fungus & Cluster location in the genome assembly & Number of genes in the cluster & Number of non-CAZyme genes in the cluster \\
\hline \multirow[t]{3}{*}{ P. radiata } & Unitig 6/Scaffold 23:237827-242972 & 2 & 0 \\
\hline & Unitig 9/Scaffold 8:1780628-1784094 & 2 & 0 \\
\hline & Unitig 83/Scaffold 30:124277-133397 & 4 & 1 \\
\hline \multirow[t]{3}{*}{ P. brevispora } & Scaffold 7:1939036-1942768 & 2 & 0 \\
\hline & Scaffold 8:1713073-1722627 & 4 & 1 \\
\hline & Scaffold 9:703327-712085 & 3 & 1 \\
\hline P. centrifuga & Scaffold 809:16725-20452 & 2 & 0 \\
\hline \multirow[t]{4}{*}{ B. adusta } & Scaffold 3:699996-705149 & 3 & 0 \\
\hline & Scaffold 12:565705-571395 & 3 & 0 \\
\hline & Scaffold 19:267134-284710 & 9 & 2 \\
\hline & Scaffold 35:28836-31774 & 2 & 0 \\
\hline \multirow[t]{3}{*}{ P. gigantea } & Scaffold 13:72697-82083 & 4 & 2 \\
\hline & Scaffold 167:19857-23789 & 2 & 0 \\
\hline & Scaffold 240:27459-32596 & 3 & 0 \\
\hline \multirow[t]{2}{*}{ P. carnosa } & Scaffold 3:465671-473281 & 3 & 0 \\
\hline & Scaffold 10:958421-970775 & 4 & 2 \\
\hline \multirow[t]{2}{*}{ P. chrysosporium } & Scaffold 7:1587181-1592893 & 4 & 1 \\
\hline & Scaffold 10:522449-536923 & 7 & 4 \\
\hline
\end{tabular}

Locations of $P$. radiata gene models are indicated as original assembly unitig positions, and as scaffold positions of the MycoCosm genome repository. Other data were retrieved from the MycoCosm

were identified in unitig 87 as separated by two intervening non-CAZyme genes. Two of these AA5 genes were up-regulated on spruce, whereas the third gene in the middle of the cluster was down-regulated. The above described clustering of functionally related or similar genes suggest that despite their close structural location in the genome, genes in the same cluster may display individual and deviated pattern of regulation of expression.

\section{Peptidases}

Annotation of the putative $P$. radiata peptidases according to the classifications in the MEROPS database [40] (https://www.ebi.ac.uk/merops/) indicated that at least 327 genes identified in the $P$. radiata genome possibly encode proteolytic enzymes (Table 5). Highest number of the genes were classified to code for serine peptidases. Among the seven phlebioid species, $P$. radiata was the only species of the genus Phebia comprising genes ( 2 genes) encoding putative glutamic peptidases. However, more than ten genes encoding glutamic peptidases were detected in the two species of Phanerochaete, and in P. gigantea.

\section{ABC transporters}

In total, a versatile set of 49 genes encoding predicted $\mathrm{ABC}$ proteins were identified in the genome assembly of P. radiata (Table 6, Additional file 7). Out of them, 40 genes encode predicted $\mathrm{ABC}$ transporters, and 9 genes encode $A B C$ proteins without any transmembrane domains. One of the 49 genes is apparently disrupted by a retrotransposon insertion (ABCF3 encoding gene) (Additional file 7). All types of $\mathrm{ABC}$ transporter encoding genes, which are commonly found in the species of Basidiomycota class Agaricomycetes could be identified $[41,42]$. Not surprisingly, the set of putative ABC proteins of $P$. radiata demonstrates high similarity with the set of $\mathrm{ABC}$ proteins found in the genomes of P. brevispora [41] and $P$. centrifuga (this study). The differences between the three species of Phlebia are merely quantitative (Table 6), probably due to a few lineage-specific cases of gene loss or duplication events.

Compared with the four other phlebioid clade species $(B$. adusta, $P$. gigantea, $P$. carnosa, $P$. chrysosporium), a few notable differences may be noticed (Additional file 8). The three species of Phlebia all possess one gene encoding a transporter of ABC-A family, whereas corresponding genes are missing from the other phlebioid species (Table 6). ABC-A transporters are likely involved in the transport of lipid molecules, and they were previously identified in most of the analyzed fungi of the Basidiomycota subphylum Agaricomycotina [41, 42]. Likewise, a soluble ABC protein classified as ABCF3 encoding gene was identified in the genomes of $P$. brevispora, $P$. centrifuga and $P$. radiata (Table 6, Additional file 8). The function of ABCF3 encoding gene is unknown, and it is apparently non-essential, since the gene is absent from ca. $40 \%$ of the analyzed species of Agaricomycotina. We could not identify the gene in the 
Table 5 Number of peptidase encoding genes identified in the genomes of the seven phlebioid fungi

\begin{tabular}{llllllll}
\hline Peptidase family Fungal species & Aspartic & Cysteine & Glutamic & Metallo & Serine & Threonine & Sum of peptidases \\
\hline P. radiata & 48 & 50 & 2 & 60 & 149 & 18 & 327 \\
P. brevispora & 67 & 59 & 0 & 73 & 207 & 19 & 425 \\
P. centrifuga & 58 & 45 & 0 & 51 & 138 & 18 & 310 \\
B. adusta & 60 & 69 & 0 & 68 & 173 & 18 & 388 \\
P. gigantea & 43 & 51 & 15 & 62 & 159 & 18 & 348 \\
P. carnosa & 70 & 91 & 34 & 61 & 170 & 17 & 443 \\
P. chrysosporium & 64 & 45 & 11 & 55 & 149 & 19 & 343 \\
\hline
\end{tabular}

Data was searched and retrieved from the MycoCosm

Phanerochaete clade, and in $P$. radiata, the corresponding gene is disrupted by an insertion of a retrotransposon, thereby most likely making it non-functional. Another gene classified as ABCG6.2 and encoding an ABC transporter of unknown function was found in $P$. chrysosporium, $P$. carnosa and P. gigantea, but not in the species of Phlebia. This gene, however, was previously identified in less than $25 \%$ of the analyzed species of Basidiomycota [41, 42]. Another notable feature of the set of $\mathrm{ABC}$ genes in $P$. radiata is a high number of $\mathrm{ABCC} 4$ encoding genes, present in eight copies in the most expanded subfamily of ABC-C proteins (Table 6, Additional file 7).

\section{Secondary metabolism genes of $P$. radiata}

Bioinformatic analysis of secondary metabolite (SM) biosynthesis-related genes of $P$. radiata indicates that the genome harbors a rich repertoire of genes putatively involved in the production of secondary metabolites. At this stage, however, no accurate chemical structures of the potential products could be inferred (Additional file 4).

\section{Polyketide synthases}

Six genes encoding predicted polyketide synthases (PKSs) were identified in the genome assembly of $P$. radiata (Pks1-6) (Additional file 4). Four were annotated as type I PKS encoding genes (Pks1, Pks2, Pks4 and Pks5), whereas two genes are predicted to encode a type III PKS (Pks6) and a hybrid PKS-NRPS (nonribosomal peptide synthase) (Pks3), respectively. Similar hybrid PKS-NRPS-encoding genes are found in a number of wood-inhabiting Basidiomycota Agaricomycetes fungi including Heterobasidion irregulare [43]. Based on the presence of conserved modules recognized in the deduced proteins, the identified type I PKSs could be further classified into one nonreducing PKS (Pks2) and three reducing PKSs. Among the three reducing type I PKS genes, Pks4 and Pks5 share $73 \%$ of amino-acid sequence identity, suggestive of a gene duplication. Two of the identified PKS encoding genes form larger SM pathway gene clusters. The non-reducing type I PKS-encoding Pks2 gene was identified next to a NRPS-like encoding Nrl6 gene (see below for the discussion of this gene family) together with three genes encoding cytochrome P450 redox enzymes and one predicted gene coding for a glycosyl transferase. Interestingly, GH76 and GH16 CAZyme genes are located close to Pks2 gene. Pks4 was observed to be clustered with the NRPS-like gene Nrl8, in addition to two genes encoding MFS transporters and several genes encoding putative tailoring enzymes, indicative of functional roles in chemical modifications of the compounds produced by the corresponding PKS enzymes.

Table 6 Number of ABC transporter encoding genes identified in the genomes of the seven phlebioid fungi

\begin{tabular}{llllllll}
\hline Fungal species / ABC Subfamily & P. radiata & P. brevispora & P. centrifuga & B. adusta & P. gigantea & P. carnosa & P. chrysosporium \\
\hline ABC-A & 1 & 1 & 1 & 0 & 0 & 0 & 0 \\
ABC-B (FL) & 3 & 3 & 4 & 4 & 3 & 3 & 3 \\
ABC-B (HT) & 8 & 6 & 6 & 8 & 9 & 7 & 8 \\
ABC-C & 18 & 26 & 20 & 13 & 19 & 18 & 18 \\
ABC-D & 2 & 2 & 2 & 2 & 2 & 2 & 2 \\
ABC-E & 1 & 1 & 1 & 1 & 1 & 5 \\
ABC-F & 5 & 5 & 5 & 7 & 5 & 5 & 5 \\
ABC-G & 8 & 8 & 7 & 7 & 6 & 3 & 1 \\
ABC-I & 3 & 3 & 3 & 3 & 3 & 3
\end{tabular}




\section{Adenylate-forming reductases}

Members of this protein family resemble non-ribosomal peptide synthases (NRPS), but lack a condensation domain [44]. Although no canonical NRPS genes were identified in the genome of $P$. radiata, however, nine genes encoding predicted adenylate-forming reductases were found. Based on their domain organization, one gene (Lys2 homolog) was identified as a putative L- $\alpha$-aminoadipate reductase, which is involved in L-lysine biosynthesis in fungi [44]. The remaining eight genes (Nrl1-8) encode adenylateforming reductases of unknown function, and several of them are clustered with other SM encoding genes: Nrl1 is clustered with a predicted terpene cyclase, Nrl6 and Nrl8 are located close to the predicted PKS genes, Nrl7 is adjacent to a cytochrome P450 encoding gene, whereas the genes for $\mathrm{Nrl} 2, \mathrm{Nrl} 3$ and $\mathrm{Nrl} 4$ form a cluster on their own, with near location to the gene for Nrl5. Interestingly, a GH12 endoglucanase gene, putative AA3 alcohol oxidase and aryl-alcohol oxidase encoding genes, and a GH131 cellulase gene are found close to the cluster of $\mathrm{Nrl} 2, \mathrm{Nrl} 3$ and $\mathrm{Nr} 14$. In addition, the gene for $\mathrm{Nrl} 7$ adenylate-forming reductase was recognized to be located next to an AA9 family LPMO encoding gene. Interestingly, expression of this AA9 gene was not up-regulated on spruce wood substrate [26] indicating a distinct function for the specific AA9 enzyme other than attack on the cellulose polymer. Within the gene clusters involved in SM biosynthesis, genes encoding various oxidases indicate their functional activity in modifications of the products of the SM pathways.

\section{Terpene cyclases}

Predicted terpene compound forming terpenoid cyclases (TC) [45] constitute the most numerous group of the identified SM biosynthesis involved genes in the genome of $P$. radiata. In total, 16 putative TC encoding genes (Ter1-Ter16) were identified, of which one (Ter16) could encode a squalene synthase. The products of remaining genes are unknown. Many of the TC genes are located in clusters: Ter5, Ter6 and Ter7 and Ter8 - Ter11 form two separate clusters on unitig70; Ter14 clusters with Ter15, and Ter1 is located next to the adenylate-forming reductase encoding gene Nrl1. There is a CAZyme gene cluster close to the cluster of Ter8-Ter11 including two GH5 genes and a putative AA3 family alcohol oxidase encoding gene. Ter2 gene is also located between two AA3 family genes and next to a cytochrome P450 gene.

\section{AMP-dependent acyl-CoA synthetases}

Our bioinformatics analysis identified two additional genes coding for unknown functions, which, based on their predicted protein domain organization, could have a role in secondary metabolism. Both genes share some similarity with AMP-dependent acyl-CoA synthetase encoding genes, and their deduced protein products enclose a NRPS-specific C-terminal domain. The function of these proteins is still obscure.

Among the multiple predicted proteins involved in biosynthesis of secondary metabolites in $P$. radiata, six genes coding for Nrl4, Pks6, Ter1, Ter3, Ter4 and Ter12 were earlier recognized as being up-regulated in the $P$. radiata transcriptomes on spruce wood substrate (at 2week and 4-week time points) [26] (Additional file 4). This indicates specific functions and involvement of chemically diverse fungal secondary metabolite compounds in active hyphal growth and colonization of wood, and potential participation in the wood decomposition processes.

\section{Small secreted proteins of $P$. radiata}

A total number of 956 genes identified in the $P$. radiata genome were predicted to encode secreted proteins, among which 215 represented small and cysteine-rich proteins (small secreted proteins, SSPs). From the in silico predicted protein secretome, 83 and 307 proteins were selected by EffectorP and LOCALIZER, respectively, as putative SSP candidates. Afterwards, all SSP candidates were merged and the annotated and predicted CAZymes were removed from the final analysis, thereby resulting in a final set of 430 candidate proteins as SSPs (Additional file 5).

The Venn diagram depicts the number of SSPs obtained according to the three criteria used (Fig. 7). Eight SSPs (genes minus.g2681, minus.g6180, plus.g1485, plus.g2909, plus.g2957, plus.g7370, plus.g8107, plus.g881) were shared by all criteria, and could be deemed as good SSP candidates for functional validation after gene structural inspection (Table 7). In the set of predicted SSPs in P. radiata, the shortest SSP candidate was only 66 amino-acids in length (gene plus.g1238.t1), while the longest protein was 1718 aa in length (gene plus.g13035.t1). The average length for the translated proteome, secretome and the selected SSPs was in descending order (487, 394 and 353 aa, Additional file 6), opposite to the average of cysteine composition in the protein models, which were $1.49 \%, 2.12 \%$ and $3.01 \%$ for the three protein sets, respectively. According to the $P$. radiata transcriptome data [26] (Additional file 5), the top up-regulated SSP genes were found to encode putative hydrophobins. Hydrophobins are surfaceactive small secreted proteins that have diverse roles in fungal hyphal and mycelial growth and lifestyles [46].

\section{Discussion}

Basidiomycota species of the phlebioid clade of the systematic order Polyporales [10,11] are wood-inhabiting fungi with biotechnological interest due to their ability to decompose all components of wood lignocelluloses, including modification and degradation of wood lignin [5, 12, 26]. Phlebioid fungi include the model species of white rot decay of wood, Phanerochaete chrysosporium [12] together 


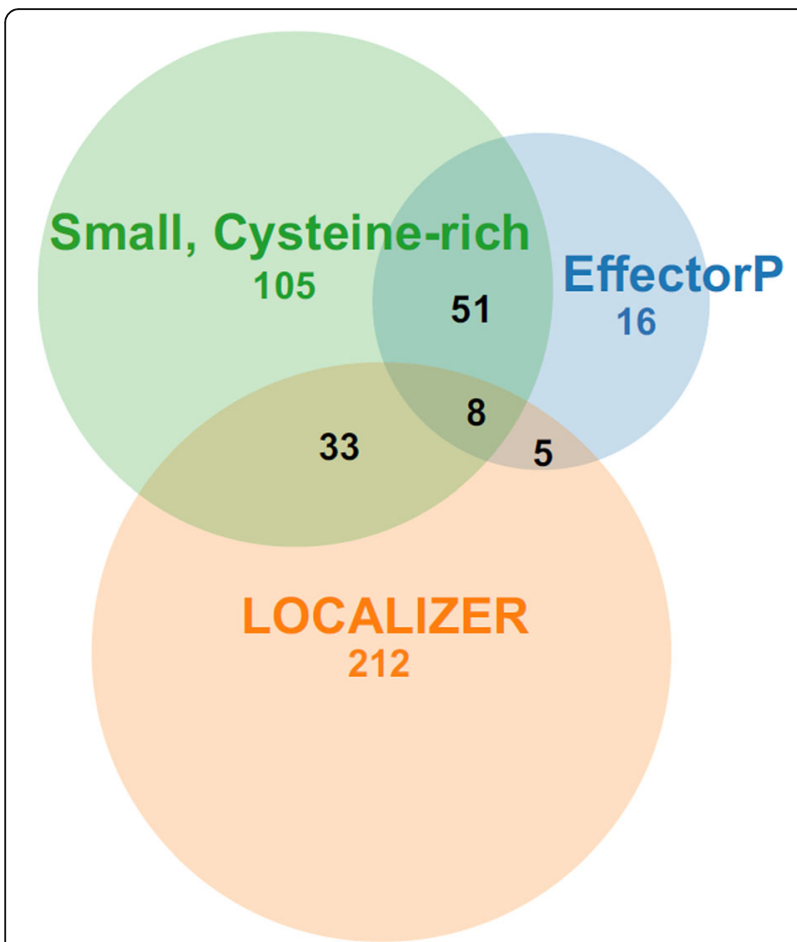

Fig. 7 Venn diagram illustrating the number of shared SSP candidates of $P$. radiata. The SSP genes were computationally analysed by using EffectorP and LOCALIZER and according to the criteria of being small and cysteine-rich

with the efficient lignin-attacking species Phlebia radiata $[18,26]$ and xenobiotics modifying species Bjerkandera adusta [7, 47], all of which are well-known producers of a large array of secreted enzymes against wood carbohydrates (CAZymes) including numerous auxiliary oxidoreductases (oxidases, laccases, peroxidases and monooxygenases) [5, 13, 33]. Especially, production of the oxidoreductases to generate extracellular ROS (reactive oxygen species) [48] and to modify lignin by production of lignin-active class-II peroxidases $[13,14,37]$ are characteristics of the phlebioid species. The strong ability for production of ROS and oxidoreductases inherent among phlebioid fungi facilitates the attack on lignin and crystalline cellulose which furthermore allows access to the more easily degradable and utilizable plant biomass polysaccharides.

Of the phlebioid species selected for this comparative study, $P$. chrysosporium has been the most extensively studied and was the first genome of Basidiomycota fungus to be sequenced in early 2000 [12]. Since then, hundreds of Basidiomycota including over 80 species of the order Polyporales have been genome sequenced in the 1000 Fungal Genomes project (JGI MycoCosm https:// genome.jgi.doe.gov/programs/fungi/index.jsf) [16, 49]. The sequenced and annotated phlebioid clade species of Polyporales comprise one or a few species of the genera Phanerochaete, Phlebia, Phlebiopsis, and Bjerkandera. Although the phlebioid fungi are deadwood and woody debris colonizing and decomposing species, they deviate in their ecological and physiological characteristics. $P$. chrysosporium has been mainly isolated from hardwoods (angiosperm wood) whereas Phanerochaete carnosa usually inhabits softwood (coniferous wood) [29]. Phlebiopsis gigantea is considered as a pioneer colonizer of softwood due to its special ability to grow into freshly exposed conifer sapwood, such as cut tree stumps, with a high content of resinous extractives, which apparently restricts substrate access for other wood-decay fungi [15]. Bjerkandera adusta in turn is a common Polyporales species in temperate European forests inhabiting dead angiosperm hardwood, such as beech, and coniferous wood. $B$. adusta is considered as a secondary or primary colonizer of attached branches, tree stumps and fallen wood [50].

Phlebia species, on the other hand, are likewise secondary or primary colonizers able to cause white rot both on coniferous and hardwood, with some substrate specificities [51, 52]. The resupinate fruiting bodies of $P$. radiata are commonly found on dead angiosperm wood such as stumps and branches of birch and rowan, whereas $P$. centrifuga is a common colonizer of dead conifers in the boreal forests of North Europe [51]. P.

Table 7 Summary of the SSP candidates of P. radiata that fulfilled the three criteria used in the analyses

\begin{tabular}{lllll}
\hline Protein coding gene ID & Length & Number of cysteines & EffectorP $^{a}$ & LOCALIZER $^{\text {b }}$ \\
\hline minus.g2681 & 265 & 10 & 0.610 & NLS \\
minus.g6180 & 200 & 6 & 0.669 & 0.998, C \\
plus.g1485 & 119 & 11 & 0.916 & NLS \\
plus.g2909 & 150 & 8 & 0.676 & $0.998, C$ \\
plus.g2957 & 146 & 8 & 0.570 & $0.896, \mathrm{C}$ \\
plus.g7370 & 229 & 19 & 0.767 & $0.716, \mathrm{C}$ \\
plus.g8107 & 158 & 8 & 0.747 & $0.971, \mathrm{C} ; 0.824, \mathrm{M}$ \\
plus.g881 & 179 & 4 & 0.781 & $0.993, \mathrm{C} ; 0.995, \mathrm{M}$ \\
\hline
\end{tabular}

${ }^{\mathrm{a}}$ The number is the probability of being an effector given by EffectorP

${ }^{\mathrm{b}}$ The number is the probability of having a Chloroplast (C) transit peptide-like or Mitochondria (M) transit peptide-like sequences given by LOCALIZER; for the cases of searching for nuclear localization signals (NLS), no probability was returned 
brevispora was described as a new species causing substantial white rot decay in pine wood in North America [52]. Thus, by the aid of comparative genomic analyses on the wood carbohydrate and lignin active CAZyme encoding genes, we expected to observe some differences in the gene repertoire between the seven species of taxonomically near-related and eco-physiologically specified phlebioid white-rot fungal species.

As an outcome of the complete sequencing, assembly, gene prediction and annotation of the $P$. radiata nuclear genome, a fully closed and gene dense reference genome was obtained. Most of the sequenced phlebioid genomes are draft assemblies and there has been a need for a more accurate reference genome, which will now be filled by the availability of $P$. radiata genome. The predicted gene number of $P$. radiata is the second highest among the phlebioid genomes. Specific features of the predicted proteincoding genes in $P$. radiata were the extremely short exons, even as short as two nucleotides, and many exons comprising only one codon (three nucleotides). For example, the glycolytic core metabolic GAPDH enzyme encoding gene begins with the first start codon exon followed by the immediate first intron (gene plus.g5457). In addition, the 5' UTRs of the annotated genes of $P$. radiata typically contain putative upstream open reading frames (uORFs). In fungal mRNAs, uORFs are fairly common and are believed to have for example regulatory roles for gene expression and possibly an effect on mRNA stability [53].

Exploring the CAZyme gene content among the seven phlebioid fungi revealed gene sets typical for white rot Basidomycota fungi of the class Agaricomycetes $[5,7,8,13,28,30]$ encoding an array of secreted cellulases, hemicellulases, pectinases, auxiliary oxidoreductases and lignin-modifying enzymes. In addition to the conventional cellobiohydrolase encoding genes of the families GH6 (1 gene in phlebioid genomes) and GH7 (3-8 genes in each fungus), all the studied genomes harbor GH131 genes belonging to a novel CAZy family, which includes unusual hydrolases with bifunctional exo- $\beta-1,3-/-1,6-$ and endo- $\beta-1,4$ activities towards a wide range of $\beta$ glucans including also cellulosic derivatives [54]. Another unconventional cellulase encoding gene present in the phlebioid genomes belongs to the family GH9. The $P$. chrysosporium GH9 gene has been cloned and characterized [55] and GH9 enzyme of the bacterium Clostridium cellulosi was recently described as a processive endoglucanase [56]. It is of interest that the brown rot fungal genomes of Polyporales seemingly lack GH9 genes [57]. Thus, it may be proposed that the higher degree of hydrolytic enzyme diversity against cellulose gives an advantage for the white rot phlebioid fungi for efficient decomposition of wood lignocellulose.

The CAZy family AA9 lytic polysaccharide monooxygenases attack and cleave polymeric cellulose via oxidative and oxygen atom incorporating mechanism [48, 58, 59] and may also act on hemicelluloses [60]. The AA9 lpmo genes are expanded in white rot Polyporales fungi [57], and accordingly, the studied phlebioid genomes contained over 10 annotated lpmo AA9 genes. Especially notable is the large number of AA9 family genes (up to 28 genes) in B. adusta. The novel auxiliary enzyme LPMO family AA14 encoding genes were additionally identified in the seven phlebioid genomes, indicative of enzyme activities necessary for efficient white rot fungal lifestyle, although the number of genes (2-3) was much lower than annotated for the AA9 family LPMOs. The family AA14 LPMOs were recently discovered to present oxidative reaction against the heteroxylan shield covering cellulose microfibrils [35], thus potentially facilitating access to cellulose backbone for the cellulolytic enzymes.

Taking into account the recent finding of activation of LPMOs preferentially by hydrogen peroxide (rather than dioxygen) $[48,61]$, and the requirement of hydrogen peroxide as the primary oxidant for the CAZy family AA2 lignin-attacking class-II peroxidases [5, 37], enzymatic production of $\mathrm{H}_{2} \mathrm{O}_{2}$ and other ROS for biological decomposition of lignocellulose is of utmost importance. Of the various auxiliary oxidoreductase enzymes, the potential hydrogen peroxide producing GMC flavoprotein family AA3 is presented with 23-39 genes in the phlebioid fungi, and all the studied genomes harbor one $c d h$ gene encoding a cellobiose dehydrogenase ( $\left.\mathrm{CDH}, \mathrm{AA} 3 \_1\right)$. The specific function of the hybrid flavo-hemoprotein $\mathrm{CDH}$ is still unclear; in addition to possibly participating in lignin conversion, the enzyme may be involved in attack on cellulose and hemicellulose in cooperation with LPMOs [62, 63].

A wide range of activities are needed for the degradation of the complex hemicellulose polymers $[64,65]$. Endo-xylanases and mannanases cut the polymeric xylan and mannan backbone, respectively, whereas mannosidases and xylosidases release monomeric sugars. For example, acetyl xylan esterases, acetyl esterases, glucuronyl esterases, glucuronidases, galactosidases, fucosidases and arabinofuranosidases are needed for releasing the various linkages and side chains moieties present in chemically and structurally diverse hemicelluloses [64]. Genes encoding all activities necessary for hemicellulose decomposition were detected in the studied phlebioid genomes, although some differences in the set of genes were observed. For example, the CAZy family GH29 $\alpha$ fucosidase encoding genes were present only in the Phlebia species, and interestingly, these enzymes could be important in the early phases of wood colonization [9, 43]. Furthermore, the family GH11 endoxylanases may 
imply specific functions due to their uneven distribution as corresponding genes among the phlebioid genomes. In the case of $P$. gigantea, the lack of GH95 $\alpha$-fucosidase encoding genes (1-3 genes in other phlebioid genomes) as well as the abundance of CE8 pectin methylesterase encoding genes were noticed in the previous genome description study [15].

The phlebioid genomes possess key genes encoding activities against lignin including genes of AA2 family class II peroxidases together with genes of AA3, AA4, AA5 families encoding proteins for production of hydrogen peroxide. The genera Phlebia, Phanerochaete and Bjerkandera present various types of $\mathrm{MnP}$ and LiP enzymes, including one VP in B. adusta [14], whereas Phlebiopsis gigantea genome is restricted to short- and atypical MnPs [15]. It is evident that the class-II heme peroxidases are necessary for oxidation and modification of lignin [37], and the appearance of the first class-II peroxidase gene in the ancestor of Agricomycetes 290 million years ago initiated decomposition of wood lignin and white rot lifestyle [13].

Notably, expansion in the number of AA2 class-II peroxidase encoding genes (10-21 genes per genome) were annotated with several enzymes produced and secreted on wood substrates in the most efficient white rot colonizers and lignin-degrading fungi (Phanerochaete chrysosporium, P. carnosa, Phlebia radiata, Bjerkandera adusta) [12, 13, $26,29,57]$. The expansion of AA2 lignin-modifying peroxidase and dye-decolorizing peroxidase (DyP) to 21 and 10 genes, respectively, in B. adusta was previously documented [14]. The evolutionary analysis suggested that the ancestor of Agaricomycetes possessed one to two genes for class-II peroxidases, and one to two genes coding for dyedecolorizing peroxidases [13]. The number of DyP encoding genes in the phlebioid fungi has expanded from one to four genes in P. gigantea and to ten genes in B. adusta, whereas the efficiently lignin-attacking species $P$. chrysosporium has evidently lost this gene. Thus, it may be concluded that on the contrary to the class-II LiP, MnP and VP peroxidases, DyP enzymes are not essential for oxidization and degradation of lignin.

Overall, the CAZyme gene content of the studied fungal genomes was quite constant, with over 150 annotated genes per genome, which is expected from closely related fungi with similar, white-rot decay and wood inhabiting lifestyles. However, some fine-tuning of plant cell wall degradation activities may be proposed from the subtle differences detected, especially in the number of CAZyme genes coding for enzyme activities against hemicelluloses. In addition, the family GH44 endoglucanase encoding genes were found to be specific for the three Phlebia species. Moreover, genomic clustering of especially AA9 lpmo genes and GH10 xylanase encoding genes was noticed to be common among the phlebioid fungi, which may imply concerted regulation of gene expression [66].

Phylogenetic conservation of specific gene clusters pinpoints their importance in the fitness for fungi in their environments, and thereby, preservation in the course of evolution [67]. Clustering of lignin-modifying peroxidase and copper radical oxidase genes of $P$. chrysosporium has been recognized previously [12], whereas clustering of cellulase encoding genes was less evident. Similarly, clustering of the P. carnosa MnP and LiP encoding genes has been observed, whereas most of the CAZyme genes were loosely associated [29]. In P. radiata, we noticed in this study similar features of clustering of LiP encoding genes (two genes) and likewise noticed in P. chrysosporium, together with AA5 copper radical oxidase encoding genes (three genes). For gene clustering and co-expression, several explanations may be proposed. First, the neighboring genes may locate in the genome on the same euchromatin or heterochromatin segment, or the co-expressed genes may contain a common transcription factor binding site (on the promoter region) or even share the same promoter [66]. However, as clustering of genes is not necessary for co-expression, the true purpose of gene clustering may be positioning the physiologically important and beneficial genes into chromosomal areas of low recombination rate in the fungal genomes [38, 67].

A holistic study of the transcriptome and proteome of $P$. radiata was recently conducted, which confirmed that all proteins necessary for the white-rot type of decay are produced on solid spruce wood, and their corresponding genes were up-regulated [26]. The time scale analysis of proteomics revealed that several lignin-modifying class-II peroxidases together with glyoxal and alcohol oxidases were abundantly produced at earlier growth stage on wood, indicating an initial oxidative attack against lignin units. Dynamic changes in quantities of especially LiP and $\mathrm{MnP}$ enzymes were detected during the six-week cultivation on wood. $P$. radiata is also able to activate its wood decomposing enzymatic machinery under oxygen-limited cultivation atmosphere in order to bioconvert lignocellulosic waste materials while simultaneously producing ethanol and other metabolites $[68,69]$.

Of the multitude of protein-degradative activity (peptidase) encoding genes recognized in P. radiata genome, secreted peptidases produced during the six-week cultivation on spruce wood were previously identified in the proteome [26], and the abundance of peptidases was shown to increase over time. Together with an increase in the abundance of peptidases in the proteome on wood, the simultaneous increase of e.g. chitinases [26] indicated that the fungal cell wall is undergoing reorganization and essential nutrients, predictably mainly nitrogen compounds, were recycled upon growth on wood. The most abundant peptidases detected belong to the $\mathrm{A} 01 \mathrm{~A}$ and $\mathrm{T} 01 \mathrm{~A}$ 
subfamilies according to the MEROPS classification. In this study, annotation of the peptidase encoding genes revealed that $P$. radiata genome encodes 31 and 11 putative members of the peptidase A01A and T01A families, respectively, which explains their dominance in the expressed proteome on wood. The most abundant peptidases identified from the proteome included a M28 metalloprotease, an A01 aspartyl peptidase and an S53 tripeptidyl peptidase [26].

The diversity of genes potentially involved in biosynthesis of secondary metabolites (SM) observed in P. radiata is quite uncommon for a white rot Polyporales and class Agaricomycetes fungal species $[8,15]$, which is an indication of the ability of $P$. radiata to produce a diverse set of secondary metabolites. Altogether, genes for polyketide synthase, adenylate-forming reductase, terpene cyclase, and putative AMP-dependent acyl-CoA synthetase were identified and annotated in the genome of $P$. radiata. Protein family of adenylate-forming reductases is present in the $\mathrm{Ba}$ sidiomycota species, but the functions of these enzymes in fungi are not entirely understood [70]. Clustering of the secondary metabolism genes is commonly observed in fungi, which may contribute to the regulation of genes belonging to a single SM pathway [71]. The occurrence of secondary metabolism genes close to CAZyme genes, which was observed in $P$. radiata for a few occasions, has likewise been noted in the Ascomycota species Trichoderma reesei although the possible biological reason for this coincidence is not yet known [38, 72].

Effectors secreted by fungal plant pathogens during colonization of the host are well known examples of small secreted proteins (SSPs) [73, 74]. However, the role of SSPs in the lifestyle of saprotrophic fungi such as in the seven wood decay phlebioid species of this study, is still enigmatic. A recent study suggests that some of the SSPs identified in Basidiomycota genomes could participate in the lignin-attacking system [75]. Other possible roles for SSPs are development of multicellular structures, and coping with toxic compounds present in the environment [76] or perhaps, involvement in the interspecific fungal interactions. For example, one of the $P$. radiata genes predicted to encode a SSP (plus.g7370) is homologous with the priA gene Lentinula edodes for which a role during the early stage of fruiting body formation has been proposed [77].

One intriguing notion previously was the high expression level of hydrophobin-coding genes in $P$. radiata during colonization of spruce wood [26]. Hydrophobins are a large family of secreted proteins unique to filamentous fungi [78]. These proteins function by forming into polymeric, water-repellent monolayers at the surface of aerial structure such as spores, hyphae and fruiting bodies [78]. The surface (rodlet) layer coating the conidial spores of the pathogenic Ascomycota filamentous fungal species Aspergillus fumigatus was found to mask their recognition by mammalian immune system, thereby rendering silencing of immune response [79]. In the rice blast Ascomycota fungus Magnaporthe grisea, hydrophobins have been considered as pathogenicity factors involved in conidial development and viability, appressorium formation, infectious growth in host cells and possibly in cell wall assembly [80]. Our data could provide an example of more roles of hydrophobins in the Basidiomycota and in general, in saprotrophic fungi.

Analysis of putative $\mathrm{ABC}$ transporters indicated that the set of $P$. radiata $\mathrm{ABC}$ genes identified in the genome is characteristic for the species of the Basidiomycota subphylum Agaricomycotina [41, 42]. A notable feature of the set of $\mathrm{ABC}$ genes in $P$. radiata is a high number of genes coding $\mathrm{ABCC} 4$ transporters, particularly present in eight copies in the most expanded $A B C-C$ subfamily, but all genes and their protein products of yet unknown function. Previous phylogenetic analysis indicates that numerous lineage-specific duplication events of this gene occurred in the evolution of Agaricomycotina [41], but their functional significance remains obscure. The subfamily of $\mathrm{ABC}-\mathrm{C}$ transporters of unknown function, are depicted in great variation in copy number among Agaricomycotina. The gene is present in a single copy in about one third of the analyzed species, but in some species, in particular in the members of Polyporales, more than 10 genes are recognized [41], which furthermore implies the necessity of a versatile set of transporter proteins for saprotrophic lifestyle wooddecay fungi to enable efficient nutrient uptake and metabolic activity in their harsh habitats.

In conclusion, it may be inferred that the genome of Phlebia radiata undoubtedly places the fungus and species among the phlebioid clade of Polyporales, class Agaricomycetes, within the fungal phylum Basidiomycota. Especially the comparative genomic analyses of the sets of CAZyme and auxiliary oxidoreductase enzyme encoding genes among the seven phlebioid fungal genomes emphasize the significance of the wide array of genes for activities against all polymeric components of plant cell wall (cellulose, hemicelluloses, pectin, lignin) for a saprotrophic, white rot type of wood decay strategy, and successful lifestyle in the forest environments.

Importantly, many CAZyme genes were clustered in the genome, and interestingly, some CAZyme genes show near location with secondary metabolism biosynthesis genes, which suggests potential co-expression and functional roles for the produced metabolites in inhabitation and decomposition of wood by $P$. radiata. New findings on the abundance and versatility of the $A B C$ transporter and small secreted protein encoding genes will aid in identifying them more extensively in the fungal genomes and transcriptomes. Our comparative approach and bioinformatic results are adding up the 
fundamental knowledge on fungal genomics and biology, which may be employed in research on fungal metabolic processes and bioconversions, as well as a source for new genes and proteins for biotechnology applications.

\section{Methods}

Fungal strain and isolation of DNA

Phlebia radiata Fr. isolate 79 (FBCC0043) was originally isolated from a decaying grey alder (Alnus incana) trunk in South Finland, and is deposited in the Microbial Domain Biological Resource Centre HAMBI (HAMBI-FBCC subcollection, kotka.luomus.fi/culture/fbcc) of the University of Helsinki. Identification of the isolate has been verified by ITS-PCR $[10,81]$. The isolate was cultivated and maintained on malt extract $(2 \% \mathrm{w} / \mathrm{v})$ agar at $25{ }^{\circ} \mathrm{C}$ and in the dark throughout the study. For isolation of total DNA, $P$. radiata was cultivated in liquid malt extract $(2 \% \mathrm{w} / \mathrm{v})$ medium for 7-14 days at $25^{\circ} \mathrm{C}$ in the dark after which the mycelium was harvested, frozen to $-20{ }^{\circ} \mathrm{C}$ and lyophilized. Isolation of genomic DNA was initiated with CTABsupplemented incubation of fine ground mycelium followed by phenol-chloroform purification, RNAse treatment, and final precipitation in pure cold ethanol [82].

\section{Genome sequencing, assembly and gene prediction}

Prior to sequencing, purity and molecular size distribution of total DNA (2.0 mg) was analysed by Qubit (Thermo Scientific) and Bioanalyzer (Agilent Technologies). PacBio single molecule, real-time (SMRT) sequencing technology (Pacific Biosciences of California) was the basic method used to obtain long nucleotide reads for de novo assembly of the genome. In total, 9 SMRT cells were run which yielded 702780 reads with N50 read length of $9384 \mathrm{bp}$ and a total of 4.29 Gbases of nucleotide sequence data. HGAP3 from SMRT Analysis v2.3 suite was used with 6 $000 \mathrm{bp}$ seed read length to assemble the genome. The assembly was polished with three subsequent runs of SMRT Analysis re-sequencing pipeline with Quiver consensus algorithm. Low coverage $(<5 \mathrm{X})$ and redundant, such as ribosomal only, short contigs were removed. Strandspecific paired-end Illumina RNA-Seq data described in [26] was mapped against the final assembly of genome sequence using the splice-aware RNA-Seq aligner STAR [83]. Mapped RNASeq data was filtered using the following parameters: 1) both R1 and R2 were properly mapped, 2) insert size between the reads was more than $500 \mathrm{bp}$, and 3) the mapping quality was 255 . The cleaned RNASeq bam file was finally divided into plus and minus strand read pairs based on the strand-specific nature of the libraries (R2 data corresponding the gene transcription orientation) before genome annotation. Coding sequences of protein-coding gene models were predicted by the BRAKER1 software [84] using the plus and minus strand RNA-Seq evidence separately, and functionally annotated by blastp (version 2.2.30) [85] searches against the NCBI non-redundant protein sequences database, by PANNZER [86] and by Blast2GO [87] software. Gene models of interest were manually curated.

\section{GO enrichment analysis}

For functional prediction, GO enrichment analysis based on Fisher's exact test was conducted by using Blast2GO [87] with data from our previous transcriptome study [26]. Filter mode was p-value of 0.05 for statistical significance. Genes up-regulated (p-value $<0.05, \log 2 \mathrm{FC} \geq$ 1) upon growth on spruce wood as compared with malt extract medium as substrate at the two-week and/or four-week time points of cultivation were selected for the analysis.

\section{Annotation and comparison of CAZyme and peptidase encoding genes}

$P$. radiata CAZyme genes were functionally annotated previously [26]. Majority of the CAZyme encoding genes involved in decomposition of plant cell wall lignocellulose were manually curated. Information on annotation of putative $P$. radiata peptidases according to the MEROPS peptidase database [40] (https://www.ebi.ac.uk/merops/) was collected from the Joint Genome Institute (JGI) MycoCosm fungal genomics repository [16] (https://genome.jgi.doe.gov/programs/fungi/index.jsf). For comparative genomics of the CAZyme and peptidase genes, genetic information of the phlebioid fungi Phlebia brevispora (HHB-7030 v1.0), Phlebia centrifuga (FBCC195), Phlebiopsis gigantea (11061_1 CR5-6 v1.0), Bjerkandera adusta (HHB-12826-SP v1.0), Phanerochaete chrysosporium (RP-78 v2.2) and Phanerochaete carnosa (HHB10118-Sp v1.0) was downloaded from the JGI MycoCosm.

\section{Genes for secondary metabolism and $A B C$ transporters} Identification of the secondary metabolism-related genes in $P$. radiata genome was performed using antiSMASH prediction platform [88] with the default settings for fungal genomes followed by manual curation and annotation of the identified genes. P. radiata ABC proteincoding genes were identified by multiple tblastn and blastp searches against the genome assembly and a set of predicted proteins, respectively. Sequences of previously identified $P$. brevispora ABC proteins [41] were used as queries. All hits producing E-values below $10^{-6}$ were further examined. Gene models were manually $\mathrm{cu}$ rated and, when necessary, the positions of $\mathrm{N}$ and $\mathrm{C}$ termini were adjusted. For gene number comparisons, the number of $\mathrm{ABC}$ transporter genes of the studied phlebioid fungi was obtained from the previous study [41]. The putative $\mathrm{ABC}$ transporter genes of $P$. centrifuga were then identified by blastp searches against the 
genome sequence deposited in the MycoCosm with the $P$. radiata $\mathrm{ABC}$ proteins as queries.

\section{Small secreted proteins}

Secreted proteins were identified using SignalP v.4.1 (sensitive mode) [89], TargetP v.1.1 [90] and TMHMM v.2.0 [91] to predict the presence of signal peptide, targeted cellular localization and transmembrane domain (TM), respectively. Proteins having more than two TMs and or having a single TM not overlapping with the signal peptide (outside the first 60 amino acids) were excluded. Subsequently, the predicted secretome was submitted to EffectorP v.2.0 [92] and LOCALIZER v.1.0 [93]. EffectorP could help prioritize the selection of highly confident effector candidates. LOCALIZER aids the prediction of translocation of fungal effectors into plant chloroplasts, mitochondria and nuclei based on the presence of transit peptides and nuclear localization signals. In addition, secreted proteins with length $<300$ amino acids and cysteine residues $\geq 4$ were also selected. All three sets of putative proteins were merged and constituted the final SSP list after removing the putative secreted CAZymes.

\section{Recognition of genomic clustering and co-expression of CAZyme genes}

Co-localization of $P$. radiata CAZyme genes in the genome assembly were searched according to unitig number and nucleotide start and end positions of the predicted gene models. Minimum of three CAZyme genes in a window of maximum of 11 genes was considered as a cluster. Size of the window was calculated according to [38]. Common expression patterns i.e. up-regulation at 2 and 4 weeks of growth on spruce wood substrate as compared with malt extract liquid medium were identified [26]. Co-localization of the GH10 and AA9 family genes of $P$. brevispora, $P$. centrifuga, $P$. gigantea, $B$. adusta, $P$. chrysosporium and $P$. carnosa was investigated with the graphical display of the JGI Genome Browser (https://genome.jgi.doe.gov/help/browser_main.jsf) by visualizing the clusters of the CAZyme gene models positioned along each genome assembly scaffold. Maximum number of three non-CAZyme genes was allowed between the genes forming the cluster.

\section{Additional files}

Additional file 1: GO enrichment analysis of $P$. radiata genes upregulated in the presence of spruce wood. Statistically significant upregulation ( $p$-value $<0.05, \log 2 F C \geq 1$ ) was analyzed previously [26] as compared with malt extract cultivation at the two week ( $2 \mathrm{w}$ upregulated) and/or four week ( $4 \mathrm{w}$ up-regulated) time points of cultivation. (XLSX $11 \mathrm{~kb}$ )

Additional file 2: $P$. radiata gene models encoding CAZymes, their locations in the genome assembly together with transcriptome data and proteome data from spruce wood cultivations [26]. 2w, two week time point of the spruce wood cultivation; $4 \mathrm{w}$, four week time point of the spruce wood cultivation; up, up-regulated; down, down-regulated. (XLSX $44 \mathrm{~kb})$

Additional file 3: $P$. radiata gene models encoding plant cell wall attacking CAZymes and located in clusters in the genome assembly. Fold change of expression of the genes in spruce wood cultivations as compared with malt extract cultivations at the two week $(2 \mathrm{w})$ and four week (4w) time points of cultivation was analyzed previously [26]. (XLSX $22 \mathrm{~kb})$

Additional file 4: Putative secondary metabolism genes identified from the $P$. radiata genome assembly. Fold change of expression of the genes in spruce wood cultivations as compared with malt extract cultivations at the two week ( $2 w)$ and four week (4w) time points of cultivation was analyzed previously [26]. (XLSX $15 \mathrm{~kb})$

Additional file 5: Putative small secreted proteins of $P$. radiata chosen according to EffectorP analysis, LOCALIZER analysis and by identifying small cysteine rich protein. Fold change of expression of the genes in spruce wood cultivations as compared with malt extract cultivations at the two week ( $2 \mathrm{w})$ and four week ( $4 \mathrm{w}$ ) time points of cultivation was analyzed previously [26]. (XLSX $40 \mathrm{~kb})$

Additional file 6: Distribution of length of Phlebia radiata whole proteome, secretome and SSPs. Numbers on the bar denote the average length of each set of protein sequences. (PDF $19 \mathrm{~kb}$ )

Additional file 7: $A B C$ transporter genes identified from the $P$. radiata genome assembly. (XLSX $117 \mathrm{~kb}$ )

Additional file 8: Comparisons of the numbers of $A B C$ transporter genes between different species of Agaricomycotina. (XLSX $23 \mathrm{~kb}$ )

\section{Abbreviations}

AA: Auxiliary activity redox enzyme; CAZyme: Carbohydrate-active enzyme; CE: Carbohydrate esterase; GH: Glycoside hydrolase; LiP: Lignin peroxidase; LPMO: Lytic polysaccharide monooxygenase; MnP: Manganese peroxidase; NRPS: Non-ribosomal peptide synthase; nt: Nucleotide; PKS: Polyketide synthase; PL: Polysaccharide lyase; SM: Secondary metabolism

\section{Acknowledgements}

Outi-Maaria Sietiö is thanked for the aid in purification of $P$. radiata DNA for genome sequencing. Igor Grigoriev at DOE JGI, USA, is thanked for collaboration and accepting the annotated genome assembly as submission to the MycoCosm repository.

\section{Authors' contributions}

$T L, J K, L P, P A$ and FOA designed the study. JK performed fungal cultivations and DNA and RNA extractions. LP managed sequencing and data collection. OPS and PL assembled $P$. radiata genome and performed gene model prediction. MM and JK annotated and manually curated CAZyme gene models, and performed comparative protein analyses. MM analyzed GO enrichment and genomic clustering. AK annotated the secondary metabolism and $A B C$ transporter genes. $Z Z$ annotated the small secreted protein genes. TL, PA and FOA supported materials. MM and TL wrote and edited the manuscript. All authors read and approved the final manuscript.

\section{Funding}

This study was financed by the Academy of Finland project Grants No. 138331 and 285676 to $\mathrm{TL}$, and 276862 to FOA.

\section{Availability of data and materials}

The annotated $P$. radiata genome assembly is available at the Joint Genome Institute (JGl) MycoCosm repository (https://genome.jgi.doe.gov/Phlrad1/ Phlrad1.home.html). All data generated and analysed in the study are included in this published article and its supplementary information files.

Ethics approval and consent to participate

Not applicable.

Consent for publication

Not applicable. 


\section{Competing interests}

The authors declare that they have no competing interests.

\section{Author details}

'Department of Microbiology, Faculty of Agriculture and Forestry, Viikki Campus, University of Helsinki, Fl-00014 Helsinki, Finland. ²DNA Sequencing and Genomics Laboratory, Institute of Biotechnology, Viikki Campus, Fl-00014 Helsinki, Finland. ${ }^{3}$ Department of Forest Sciences, Faculty of Agriculture and Forestry, University of Helsinki, Viikki Campus, Fl-00014 Helsinki, Finland. ${ }^{4}$ Present address: VTT Technical Research Centre of Finland Ltd., Espoo, Finland. ${ }^{5}$ Present address: Department of Chemistry and Biotechnology, Division of Gene Technology, Tallinn University of Technology, Tallinn, Estonia.

Received: 7 March 2019 Accepted: 21 May 2019

Published online: 28 May 2019

\section{References}

1. Boerjan W, Ralph J, Baucher M. Lignin biosynthesis. Annu Rev Plant Biol. 2003;54:519-46. https://doi.org/10.1146/annurev.arplant.54.031902.134938.

2. Gillet S, Aguedo M, Petitjean L, Morais ARC, da Costa Lopes AM, Łukasik RM, et al. Lignin transformations for high value applications: towards targeted modifications using green chemistry. Green Chem. 2017;19:4200-33. https:// doi.org/10.1039/C7GC01479A

3. Hibbett DS, Binder M, Bischoff JF, Blackwell M, Cannon PF, Eriksson OE, et al. A higher-level phylogenetic classification of the Fungi. Mycol Res. 2007;111: 509-47. https://doi.org/10.1016/J.MYCRES.2007.03.004.

4. McLaughlin DJ, Hibbett DS, Lutzoni F, Spatafora JW, Vilgalys R. The search for the fungal tree of life. Trends Microbiol. 2009;17:488-97. https://doi.org/ 10.1016/J.TIM.2009.08.001.

5. Lundell TK, Mäkelä MR, de Vries RP, Hildén KS. Genomics, lifestyles and future prospects of wood-decay and litter-decomposing Basidiomycota. Adv Bot Res. 2014;70:329-70. Fungi. Elsevier. https://doi.org/10.1016/B978-0-12397940-7.00011-2.

6. Baldrian P. Microbial activity and the dynamics of ecosystem processes in forest soils. Curr Opin Microbiol. 2017;37:128-34. https://doi.org/10.1016/J. MIB.2017.06.008

7. Binder M, Justo A, Riley R, Salamov A, Lopez-Giraldez F, Sjökvist E, et al Phylogenetic and phylogenomic overview of the Polyporales. Mycologia. 2013;105:1350-73. https://doi.org/10.3852/13-003.

8. Riley R, Salamov AA, Brown DW, Nagy LG, Floudas D, Held BW, et al. Extensive sampling of basidiomycete genomes demonstrates inadequacy of the white-rot/brown-rot paradigm for wood decay fungi. Proc Natl Acad Sci U S A. 2014;111:9923-8. https://doi.org/10.1073/pnas.1400592111.

9. Kuuskeri J. Genomics and systematics of the white-rot fungus Phlebia radiata: Special emphasis on wood-promoted transcriptome and proteome. University of Helsinki; 2016.

10. Kuuskeri J, Mäkelä MR, Isotalo J, Oksanen I, Lundell T. Lignocelluloseconverting enzyme activity profiles correlate with molecular systematics and phylogeny grouping in the incoherent genus Phlebia (Polyporales, Basidiomycota). BMC Microbiol. 2015;15:217. https://doi.org/10.1186/s12866015-0538-x.

11. Floudas D, Hibbett DS. Revisiting the taxonomy of Phanerochaete (Polyporales, Basidiomycota) using a four gene dataset and extensive ITS sampling. Fungal Biol. 2015;119:679-719. https://doi.org/10.1016/J.FUNBIO. 2015.04.003

12. Martinez D, Larrondo LF, Putnam N, Gelpke MDS, Huang K, Chapman J, et al. Genome sequence of the lignocellulose degrading fungus Phanerochaete chrysosporium strain RP78. Nat Biotechnol. 2004;22:695-700. https://doi.org/ 10.1038/nbt967.

13. Floudas D, Binder M, Riley R, Barry K, Blanchette R, Henrissat B, et al. The Paleozoic origin of enzymatic lignin decomposition reconstructed from 31 fungal genomes. Science. 2012;336:1715-9. https://doi.org/10.1126/science. 1221748.

14. Ruiz-Dueñas FJ, Lundell T, Floudas D, Nagy LG, Barrasa JM, Hibbett DS, et al. Lignin-degrading peroxidases in Polyporales: an evolutionary survey based on 10 sequenced genomes. Mycologia. 2013;105:1428-44. https://doi.org/10.3852/13-059.

15. Hori C, Ishida T, Igarashi K, Samejima M, Suzuki H, Master E, et al. Analysis of the Phlebiopsis gigantea genome, transcriptome and secretome provides insight into its pioneer colonization strategies of wood. PLoS Genet. 2014;10:e1004759. https://doi.org/10.1371/journal. pgen.1004759.

16. Grigoriev IV, Nikitin R, Haridas S, Kuo A, Ohm R, Otillar R, et al. MycoCosm portal: gearing up for 1000 fungal genomes. Nucleic Acids Res. 2014;42(Database issue):D699-704. https://doi.org/10.1093/nar/ gkt1183.

17. Justo A, Miettinen O, Floudas D, Ortiz-Santana B, Sjökvist E, Lindner D, et al. A revised family-level classification of the Polyporales (Basidiomycota). Fungal Biol. 2017;121:798-824. https://doi.org/10.1016/J. FUNBIO.2017.05.010.

18. Lundell T, Leonowicz A, Rogalski J, Hatakka A. Formation and action of lignin-modifying enzymes in cultures of Phlebia radiata supplemented with veratric acid. Appl Envir Microbiol. 1990;56:2623-9 http://aem.asm.org/ content/56/9/2623.short. Accessed 26 Jun 2015.

19. Mäkelä MR, Lundell T, Hatakka A, Hildén K. Effect of copper, nutrient nitrogen, and wood-supplement on the production of lignin-modifying enzymes by the white-rot fungus Phlebia radiata. Fungal Biol. 2013;117:6270. https://doi.org/10.1016/j.funbio.2012.11.006.

20. Hakala TK, Maijala P, Konn J, Hatakka A. Evaluation of novel wood-rotting polypores and corticioid fungi for the decay and biopulping of Norway spruce (Picea abies) wood. Enzyme Microb Technol. 2004;34:255-63. https:// doi.org/10.1016/j.enzmictec.2003.10.014.

21. Hofrichter M, Lundell T, Hatakka A. Conversion of milled pine wood by manganese peroxidase from Phlebia radiata. Appl Environ Microbiol. 2001; 67:4588-93. https://doi.org/10.1128/AEM.67.10.4588-4593.2001.

22. Hildén KS, Mäkelä MR, Hakala TK, Hatakka A, Lundell T. Expression on wood, molecular cloning and characterization of three lignin peroxidase (LiP) encoding genes of the white rot fungus Phlebia radiata. Curr Genet. 2006;49:97-105. https://doi.org/10.1007/s00294005-0045-y.

23. Hildén K, Martínez AT, Hatakka A, Lundell T. The two manganese peroxidases Pr-MnP2 and Pr-MnP3 of Phlebia radiata, a lignin-degrading basidiomycete, are phylogenetically and structurally divergent. Fungal Genet Biol. 2005:42:403-19. https://doi.org/10.1016/j.fgb.2005.01.008.

24. Mäkelä MR, Hildén KS, Hakala TK, Hatakka A, Lundell TK. Expression and molecular properties of a new laccase of the white rot fungus Phlebia radiata grown on wood. Curr Genet. 2006;50:323-33. https://doi.org/10. 1007/s00294-006-0090-1.

25. Saloheimo M, Niku-Paavola M-L, Knowles JKC. Isolation and structural analysis of the laccase gene from the lignin-degrading fungus Phlebia radiata. J Gen Microbiol. 1991;137:1537-44. https://doi.org/10.1099/ 00221287-137-7-1537.

26. Kuuskeri J, Häkkinen M, Laine $\mathrm{P}$, Smolander OP, Tamene F, Miettinen S, et al. Time-scale dynamics of proteome and transcriptome of the white-rot fungus Phlebia radiata: growth on spruce wood and decay effect on lignocellulose. Biotechnol Biofuels. 2016;9:192. https://doi.org/10.1186/ s13068-016-0608-9.

27. Mäkelä MR, Peng M, Granchi Z, Chin-A-Woeng T, Hegi R, van Pelt SI, et al. Draft genome sequence of the Basidiomycete white-rot fungus Phlebia centrifuga. Genome Announc. 2018;6. https://doi.org/10.1128/genomeA. 01414-17.

28. Ohm RA, Riley R, Salamov A, Min B, Choi I-G, Grigoriev IV. Genomics of wood-degrading fungi. Fungal Genet Biol. 2014;72:82-90. https://doi.org/10. 1016/j.fgb.2014.05.001.

29. Suzuki H, MacDonald J, Syed K, Salamov A, Hori C, Aerts A, et al. Comparative genomics of the white-rot fungi, Phanerochaete carnosa and $P$. chrysosporium, to elucidate the genetic basis of the distinct wood types they colonize. BMC Genomics. 2012;13:444. https://doi.org/10.1186/14712164-13-444.

30. Nagy LG, Riley R, Bergmann PJ, Krizsán K, Martin FM, Grigoriev IV, et al, Genetic bases of fungal white rot wood decay predicted by phylogenomic analysis of correlated gene-phenotype evolution. Mol Biol Evol. 2017:34:3544. https://doi.org/10.1093/molbev/msw238

31. Kohler A, Kuo A, Nagy LG, Morin E, Barry KW, Buscot F, et al. Convergent losses of decay mechanisms and rapid turnover of symbiosis genes in mycorrhizal mutualists. Nat Genet. 2015:47:410-5. https:/doi.org/10.1038/ ng.3223.

32. Aspeborg H, Coutinho PM, Wang Y, Brumer H, Henrissat B. Evolution, substrate specificity and subfamily classification of glycoside hydrolase family 5 (GH5). BMC Evol Biol. 2012;12:186. https://doi.org/10.1186/14712148-12-186. 
33. Lombard V, Golaconda Ramulu H, Drula E, Coutinho PM, Henrissat B. The carbohydrate-active enzymes database (CAZy) in 2013. Nucleic Acids Res. 2014;42:D490-5. https://doi.org/10.1093/nar/gkt1178.

34. Horn S, Vaaje-Kolstad G, Westereng B, Eijsink VG. Novel enzymes for the degradation of cellulose. Biotechnol Biofuels. 2012;5:45. https://doi.org/10. 1186/1754-6834-5-45.

35. Couturier M, Ladevèze S, Sulzenbacher G, Ciano L, Fanuel M, Moreau C, et al. Lytic xylan oxidases from wood-decay fungi unlock biomass degradation. Nat Chem Biol. 2018;14:306-10. https://doi.org/10.1038/nchembio.2558.

36. Couturier M, Navarro D, Chevret D, Henrissat B, Piumi F, Ruiz-Dueñas FJ, et al. Enhanced degradation of softwood versus hardwood by the white-rot fungus Pycnoporus coccineus. Biotechnol Biofuels. 2015;8:216. https://doi.org/ 10.1186/s13068-015-0407-8

37. Hofrichter M, Ullrich R, Pecyna MJ, Liers C, Lundell T. New and classic families of secreted fungal heme peroxidases. Appl Microbiol Biotechnol. 2010;87:871-97. https://doi.org/10.1007/s00253-010-2633-0.

38. Druzhinina IS, Kopchinskiy AG, Kubicek EM, Kubicek CP. A complete annotation of the chromosomes of the cellulase producer Trichoderma reesei provides insights in gene clusters, their expression and reveals genes required for fitness. Biotechnol Biofuels. 2016;9:75. https://doi.org/10.1186/ s13068-016-0488-z.

39. Huy ND, Le Nguyen C, Seo J-W, Kim D-H, Park S-M. Putative endoglucanase PcGH5 from Phanerochaete chrysosporium is a $\beta$-xylosidase that cleaves xylans in synergistic action with endo-xylanase. J Biosci Bioeng. 2015;119: 416-20 http://www.sciencedirect.com/science/article/pii/ S1389172314003478?via\%3Dihub.

40. Rawlings ND, Barrett AJ, Finn R. Twenty years of the MEROPS database of proteolytic enzymes, their substrates and inhibitors. Nucleic Acids Res. 2016; 44:D343-50. https://doi.org/10.1093/nar/gkv1118.

41. Kovalchuk A, Lee $\mathrm{Y}-\mathrm{H}$, Asiegbu FO. Diversity and evolution of $A B C$ proteins in basidiomycetes. Mycologia. 2013;105:1456-70. https://doi.org/ 10.3852/13-001.

42. Kovalchuk A, Kohler A, Martin F, Asiegbu FO. Diversity and evolution of ABC proteins in mycorrhiza-forming fungi. BMC Evol Biol. 2015;15:249. https://doi. org/10.1186/s12862-015-0526-7.

43. Olson Å, Aerts A, Asiegbu F, Belbahri L, Bouzid O, Broberg A, et al. Insight into trade-off between wood decay and parasitism from the genome of a fungal forest pathogen. New Phytol. 2012;194:1001-13. https://doi.org/10. 1111/j.1469-8137.2012.04128.x.

44. Kalb D, Lackner G, Hoffmeister D. Functional and phylogenetic divergence of fungal adenylate-forming reductases. Appl Environ Microbiol. 2014;80: 6175-83. https://doi.org/10.1128/AEM.01767-14.

45. Christianson DW. Structural and chemical biology of terpenoid cyclases. Chem Rev. 2017:117:11570-648. https://doi.org/10.1021/acs.chemrev.7b00287.

46. Mgbeahuruike AC, Kovalchuk A, Chen H, Ubhayasekera W, Asiegbu FO. Evolutionary analysis of hydrophobin gene family in two wood-degrading basidiomycetes, Phlebia brevispora and Heterobasidion annosum s.l. BMC Evol Biol. 2013;13:240. https://doi.org/10.1186/1471-2148-13-240.

47. Korniłłowicz-Kowalska T, Wrzosek M, Ginalska G, Iglik H, Bancerz R. Identification and application of a new fungal strain Bjerkandera adusta R59 in decolorization of daunomycin wastes. Enzyme Microb Technol. 2006;38: 583-90. https://doi.org/10.1016/J.ENZMICTEC.2005.10.009.

48. Bissaro B, Várnai A, Røhr ÅK, Eijsink VGH. Oxidoreductases and reactive oxygen species in conversion of lignocellulosic biomass. Microbiol Mol Biol Rev. 2018;82:e00029-18. https://doi.org/10.1128/MMBR.00029-18.

49. Grigoriev IV, Nordberg H, Shabalov I, Aerts A, Cantor M, Goodstein D, et al. The genome portal of the Department of Energy Joint Genome Institute. Nucleic Acids Res. 2012;40:D26-32. https://doi.org/10.1093/nar/gkr947.

50. Hiscox J, Savoury M, Toledo S, Kingscott-Edmunds J, Bettridge A, Al Waili N, et al. Threesomes destabilise certain relationships: multispecies interactions between wood decay fungi in natural resources. FEMS Microbiol Ecol. 2017; 93. https://doi.org/10.1093/femsec/fix014.

51. Kotiranta H, Saarenoksa R, Kytövuori I. Aphyllophoroid fungi of Finland. A check-list with ecology, distribution, and threat categories. Norrlinia. 2009; 19:1-223 ISBN 978-952-10-5310-8.

52. Nakasone KK, Eslyn WE. A new species, Phlebia brevispora, a cause of internal decay in utility poles. Mycologia. 1981;73:803-10. https://doi.org/10. 2307/3759792

53. Hood HM, Neafsey DE, Galagan J, Sachs MS. Evolutionary roles of upstream open reading frames in mediating gene regulation in fungi. Annu Rev Microbiol. 2009; 63:385-409. https://doi.org/10.1146/annurev.micro.62.081307.162835.
54. Lafond M, Navarro D, Haon M, Couturier M, Berrin J-G. Characterization of a broad-specificity $\beta$-glucanase acting on $\beta$-(1,3)-, $\beta-(1,4)-$, and $\beta-(1,6)$-glucans that defines a new glycoside hydrolase family. Appl Environ Microbiol. 2012;78:8540-6. https://doi.org/10. 1128/AEM.02572-12.

55. Vanden Wymelenberg A, Denman S, Dietrich D, Bassett J, Yu X, Atalla R, et al. Transcript analysis of genes encoding a family 61 endoglucanase and a putative membrane-anchored family 9 glycosyl hydrolase from Phanerochaete chrysosporium. Appl Environ Microbiol. 2002;68:5765-8. https://doi.org/10.1128/AEM.68.11.5765-5768.2002.

56. Zhang K-D, Li W, Wang Y-F, Zheng Y-L, Tan F-C, Ma X-Q, et al. Processive degradation of crystalline cellulose by a multimodular endoglucanase via a wirewalking mode. Biomacromolecules. 2018;19:1686-96. https://doi.org/10. 1021/acs.biomac.8b00340.

57. Hori C, Gaskell J, Igarashi K, Samejima M, Hibbett D, Henrissat B, et al. Genomewide analysis of polysaccharides degrading enzymes in 11 whiteand brown-rot Polyporales provides insight into mechanisms of wood decay. Mycologia. 2013;105:1412-27. https://doi.org/10.3852/13-072.

58. Hemsworth GR, Johnston EM, Davies GJ, Walton PH. Lytic polysaccharide monooxygenases in biomass conversion. Trends Biotechnol. 2015;33:747-61. https://doi.org/10.1016/j.tibtech.2015.09.006.

59. Beeson WT, Vu W, Span EA, Phillips CM, Marletta MA. Cellulose degradation by polysaccharide monooxygenases. Annu Rev Biochem. 2015;84:923-46. https://doi.org/10.1146/annurev-biochem-060614-034439.

60. Agger JW, Isaksen T, Varnai A, Vidal-Melgosa S, Willats WGT, Ludwig R, et al. Discovery of LPMO activity on hemicelluloses shows the importance of oxidative processes in plant cell wall degradation. Proc Natl Acad Sci. 2014; 111:6287-92. https://doi.org/10.1073/pnas.1323629111.

61. Müller G, Chylenski P, Bissaro B, Eijsink VGH, Horn SJ. The impact of hydrogen peroxide supply on LPMO activity and overall saccharification efficiency of a commercial cellulase cocktail. Biotechnol Biofuels. 2018;11:209. https://doi.org/10.1186/s13068-0181199-4

62. Henriksson G, Johansson G, Pettersson G. A critical review of cellobiose dehydrogenases. J Biotechnol. 2000;78:93-113. https://doi.org/10.1016/ S0168-1656(00)00206-6.

63. Courtade G, Wimmer R, Røhr ÅK, Preims M, Felice AKG, Dimarogona M, et al. Interactions of a fungal lytic polysaccharide monooxygenase with $\beta$-glucan substrates and cellobiose dehydrogenase. Proc Natl Acad Sci. 2016;113:5922-7. https://doi.org/10.1073/pnas.1602566113.

64. van den Brink J, de Vries RP. Fungal enzyme sets for plant polysaccharide degradation. Appl Microbiol Biotechnol. 2011;91:1477-92. https://doi.org/10. 1007/s00253-011-3473-2.

65. Rytioja J, Hildén K, Yuzon J, Hatakka A, de Vries RP, Mäkelä MR. Plantpolysaccharide-degrading enzymes from Basidiomycetes. Microbiol Mol Biol Rev. 2014;78:614-49. https://doi.org/10.1128/MMBR.00035-14.

66. Michalak P. Coexpression, coregulation, and cofunctionality of neighboring genes in eukaryotic genomes. Genomics. 2008;91:243-8. https://doi.org/10. 1016/J.YGENO.2007.11.002.

67. Pál C, Hurst LD. Evidence for co-evolution of gene order and recombination rate. Nat Genet. 2003;33:392-5. https://doi.org/10.1038/ ng1111.

68. Mattila H, Kuuskeri J, Lundell T. Single-step, single-organism bioethanol production and bioconversion of lignocellulose waste materials by phlebioid fungal species. Bioresour Technol. 2017;225:254-61. https://doi. org/10.1016/j.biortech.2016.11.082.

69. Mäkinen MA, Risulainen N, Mattila H, Lundell TK. Transcription of lignocellulose-decomposition associated genes, enzyme activities and production of ethanol upon bioconversion of waste substrate by Phlebia radiata. Appl Microbiol Biotechnol. 2018;102:5657-72. https://doi.org/10. 1007/s00253-018-9045-y.

70. Brandenburger E, Braga D, Kombrink A, Lackner G, Gressler J, Künzler M, et al. Multi-genome analysis identifies functional and phylogenetic diversity of basidiomycete adenylate-forming reductases. Fungal Genet Biol. 2018;112: 55-63. https://doi.org/10.1016/J.FGB.2016.07.008.

71. Brakhage AA. Regulation of fungal secondary metabolism. Nat Rev Microbiol. 2013;11:21-32.

72. Martinez D, Berka RM, Henrissat B, Saloheimo M, Arvas M, Baker SE, et al. Genome sequencing and analysis of the biomass-degrading fungus Trichoderma reesei (syn. Hypocrea jecorina). Nat Biotechnol. 2008;26:55360 https://www.nature.com/articles/nbt1403. 
73. Lo Presti L, Lanver D, Schweizer G, Tanaka S, Liang L, Tollot M, et al. Funga effectors and plant susceptibility. Annu Rev Plant Biol. 2015;66:513-45. https://doi.org/10.1146/annurev-arplant-043014-114623.

74. Raffaello T, Asiegbu FO. Small secreted proteins from the necrotrophic conifer pathogen Heterobasidion annosum s.l. (HaSSPs) induce cell death in Nicotiana benthamiana. Sci Rep. 2017;7:8000. https://doi.org/10.1038/s41598-017-08010-0.

75. Feldman D, Kowbel DJ, Glass NL, Yarden O, Hadar Y. A role for small secreted proteins (SSPs) in a saprophytic fungal lifestyle: Ligninolytic enzyme regulation in Pleurotus ostreatus. Sci Rep. 2017;7:14553. https://doi. org/10.1038/s41598-017-15112-2

76. Thuillier A, Chibani K, Belli G, Herrero E, Dumarçay S, Gérardin P, et al. Transcriptomic responses of Phanerochaete chrysosporium to oak acetonic extracts: focus on a new glutathione transferase. Appl Environ Microbiol. 2014;80:6316-27. https://doi.org/10.1128/AEM.02103-14.

77. Kajiwara S, Yamaoka K, Hori K, Miyazawa H, Saito T, Kanno T, et al. Isolation and sequence of a developmentally regulated putative novel gene, priA, from the basidiomycete Lentinus edodes. Gene. 1992;114:173-8. https://doi. org/10.1016/0378-1119(92)90571-6.

78. Bayry J, Aimanianda V, Guijarro Jl, Sunde M, Latgé J-P. Hydrophobins—unique fungal proteins. PLoS Pathog. 2012;8:e1002700. https://doi.org/10.1371/journal.ppat.1002700.

79. Aimanianda V, Bayry J, Bozza S, Kniemeyer O, Perruccio K, Elluru SR, et al. Surface hydrophobin prevents immune recognition of airborne fungal spores. Nature. 2009;460:1117-21. https://doi.org/10.1038/nature08264.

80. Kim S, Ahn I-P, Rho H-S, Lee Y-H. MHP1, a Magnaporthe grisea hydrophobin gene, is required for fungal development and plant colonization. Mol Microbiol. 2005;57:1224-37. https://doi.org/10.1111/j.1365-2958.2005.04750.x.

81. Mali T, Kuuskeri J, Shah F, Lundell TK. Interactions affect hyphal growth and enzyme profiles in combinations of coniferous wood-decaying fungi of Agaricomycetes. PLoS One. 2017;12:e0185171. https://doi.org/10.1371/ journal.pone.0185171.

82. Salavirta H, Oksanen I, Kuuskeri J, Mäkelä M, Laine P, Paulin L, et al. Mitochondrial genome of Phlebia radiata is the second largest (156 kbp) among fungi and features signs of genome flexibility and recent recombination events. PLoS One. 2014;9:e97141. https://doi.org/10.1371/ journal.pone.0097141.

83. Dobin A, Davis CA, Schlesinger F, Drenkow J, Zaleski C, Jha S, et al. STAR: ultrafast universal RNA-seq aligner. Bioinformatics. 2013;29(1):15-21. https:// doi.org/10.1093/bioinformatics/bts635.

84. Hoff KJ, Lange S, Lomsadze A, Borodovsky M, Stanke M. BRAKER1: Unsupervised RNA-Seq-Based Genome Annotation with GeneMark-ET and AUGUSTUS. Bioinformatics. 2015;32:767-9. https://doi.org/10.1093/ bioinformatics/btv661.

85. Altschul SF, Wootton JC, Gertz EM, Agarwala R, Morgulis A, Schaffer AA, et al. Protein database searches using compositionally adjusted substitution matrices. FEBS J. 2005;272:5101-9. https://doi.org/10.1111/j.1742-4658.2005. 04945.x.

86. Koskinen P, Törönen P, Nokso-Koivisto J, Holm L. PANNZER: highthroughput functional annotation of uncharacterized proteins in an errorprone environment. Bioinformatics. 2015;31:1544-52. https://doi.org/10. 1093/bioinformatics/btu851.

87. Conesa A, Gotz S, Garcia-Gomez JM, Terol J, Talon M, Robles M. Blast2GO: a universal tool for annotation, visualization and analysis in functional genomics research. Bioinformatics. 2005;21:3674-6. https://doi.org/10.1093/ bioinformatics/bti610.

88. Blin K, Wolf T, Chevrette MG, Lu X, Schwalen CJ, Kautsar SA, et al. antiSMASH 4.0-improvements in chemistry prediction and gene cluster boundary identification. Nucleic Acids Res. 2017;45:W36-41. https://doi.org/ 10.1093/nar/gkx319.

89. Petersen TN, Brunak S, von Heijne G, Nielsen H. SignalP 4.0: discriminating signal peptides from transmembrane regions. Nat Methods. 2011;8:785-6 https://www.nature.com/articles/nmeth.1701.

90. Emanuelsson O, Brunak S, Von Heijne G, Nielsen H. Locating proteins in the cell using TargetP, SignalP and related tools. Nat Protoc. 2007;2:953-71.

91. Krogh A, Larsson B, von Heijne G, Sonnhammer EL. Predicting transmembrane protein topology with a hidden markov model: application to complete genomes. J Mol Biol. 2001;305:567-80. https://doi.org/10.1006/ JMBI.2000.4315

92. Sperschneider J, Dodds PN, Gardiner DM, Singh KB, Taylor JM. Improved prediction of fungal effector proteins from secretomes with EffectorP 2.0. Mol Plant Pathol. 2018. https://doi.org/10.1111/mpp.12682.
93. Sperschneider J, Catanzariti A-M, DeBoer K, Petre B, Gardiner DM, Singh KB, et al. LOCALIZER: subcellular localization prediction of both plant and effector proteins in the plant cell. Sci Rep. 2017;7:44598. https://doi.org/10. 1038/srep44598.

\section{Publisher's Note}

Springer Nature remains neutral with regard to jurisdictional claims in published maps and institutional affiliations.
Ready to submit your research? Choose BMC and benefit from:

- fast, convenient online submission

- thorough peer review by experienced researchers in your field

- rapid publication on acceptance

- support for research data, including large and complex data types

- gold Open Access which fosters wider collaboration and increased citations

- maximum visibility for your research: over $100 \mathrm{M}$ website views per year

At $\mathrm{BMC}$, research is always in progress.

Learn more biomedcentral.com/submissions 